\title{
Clothing brand purchase intention through SNS
}

Purpose - The purpose of this research is to investigate the intention to purchase products through clothing brands' social network sites (SNS) based on the theory of planned behavior and uses-and-gratifications theory (U\&G), and the moderating effects of self-image congruity (SIC).

Design/methodology/approach - Data were collected from 1,003 followers of their favorite clothing brands' SNS. Data analysis was performed using structural equation modeling (SEM) and multi-group SEM analysis. The models were estimated from the matrices of variances and covariances by the maximum likelihood procedure using EQS 6.1.

Findings - The results highlight the positive impact of U\&G on attitude, SNS intentions and SNS use, and U\&G, SNS intentions and SNS use were seen to be the main antecedents predicting purchase intentions. Furthermore, SIC was found to have moderating effects between SNS attitude and SNS intentions, and between SNS intentions and SNS use.

Practical implications - This research can help clothing brands understand the need to generate brand beliefs, and to develop contents or events to help accomplish the transition from use to purchase.

Originality/value - This research contributes to the literature by providing a better understanding of intention to use and purchase intention through clothing brands' SNS pages. Keywords - Theory of planned behavior; Uses-and-gratifications; Self-image congruity; Social network sites; Purchase intentions.

Paper type - Research paper 


\section{Introduction}

Social Networking Sites (SNS) are a vast space where businesses and individuals interact and trade at ever-increasing rates. On average, Facebook has around 1.4 billion daily active users (Facebook, 2018). Instagram has also experienced substantial growth, going from 100 million monthly active users in early 2013 to 700 million in 2017 (Instagram, 2018). Clothing brands' SNS activity is also growing. Zara has over 25 million "Likes" on Facebook (Zara, 2017a) and 15.4 million followers on Instagram (Zara, 2017b), and Mango has 10.5 million "Likes" on Facebook (Mango, 2017a) and 6.1 million followers on Instagram (Mango, 2017b). Moreover, shopping habits and the use of information search systems are changing among consumers of clothing brands. $52 \%$ of global clothing shoppers prefer to search for information about possible purchases online, while $40 \%$ prefer to actually shop online (PwC, 2018). These trends are also true in Spain. More than $80 \%$ of online shoppers seek information through websites or brand apps, and 53\% interact on clothing brands' SNS, while the percentage of offline shoppers who connect to these SNS is $29 \%$ (PwC, 2017). These figures show that SNS could be essential to clothing-related brands as a means to understand the motivations driving customers to use their SNS and their purchase behavior while doing so.

The exponential growth of the use of digital technologies has empowered consumers of the fashion industry to interact, influence, belong to, and be part of the brands. In fact, the vast majority of consumers use digital channels before, during or after making their purchases (Lay, 2018). Thus, SNS participation has become a strong predictor of customer equity for global brands (Chae and Ko, 2016).

The clothing-related literature suggests that many consumers who visit clothing brands' SNS do so in search of websites where they can buy products (Touchette et al., 2015). In the same literature there is also strong evidence of a correlation between SNS usage and online sales through websites (Zhang et al., 2017). These consumers are informed and selective, and they look for information on social media. Consequently, social media and e-commerce could have 
already shifted consumer preferences toward immediate gratifications and heightened expectations for novelty (Lay, 2018). Accordingly, Uses-and-Gratifications theory (U\&G), the Theory of Planned Behavior (TPB), and Self-Image Congruity (SIC) have been examined in the conceptual framework.

$\mathrm{U} \& \mathrm{G}$ can predict the main motivations and gratifications consumers feel toward SNS, whereas TPB is able to predict the drivers of attitude on SNS use (Currás-Pérez et al., 2014). The third theory, SIC, can be used to study how individuals' attitude and behavior toward clothing brand's SNS could influence the way they express and match their self-image congruity with the pages of different brands' SNS (Kourouthanassis et al., 2015). Focusing more particularly on the first two, on the one hand, U\&G identifies how people use media and for what reasons (Rubin, 2009). Some studies conducted in the SNS context show that U\&G affects the affective and behavioral factors concerning participation in SNS (Sun et al., 2017). Others have identified how motivations influence the intention to use SNS (Dhir et al., 2017; Han et al., 2015; Wu et al., 2010; Zhou, 2011). On the other hand, TPB is aimed at identifying individual planned behavior, and has been employed in many previous studies that seek to determine what factors drive users' willingness to use SNS for entertainment purposes (Al Debei et al., 2013; Baker and White, 2010; Kim et al., 2016). By considering U\&G and TPB together, we think that relevant information regarding users' adoption of clothing brands' SNS and their purchase intentions will be revealed. However, both theories have only been used to measure SNS' intentions to use or use, not as antecedents of purchase intentions (Currás-Pérez et al., 2014; Dermentzi et al., 2016). Conversely, each theory alone would not be able to show the same level of information. Given that, to the best of our knowledge, no previous studies have specifically examined the influence of uses-and-gratifications on attitude and users' adoption of SNS in the context of clothing brands as antecedents of purchase intentions through SNS, additional clarification is needed in order to examine the effects of the motivational and 
behavioral factors on purchase intentions among users of clothing brands' SNS pages. Thus, the first research question is:

RQ1. How do uses-and-gratifications influence user attitude and the adoption of clothing brands' SNS pages?

It is known that in the case of clothing products, customers' SIC moderates the decisionmaking process and influences their attitudes and intentions toward a product (Haj-Salem et al., 2015). Furthermore, when customers purchase a product, they consider their own identity and self-image in association with that brand (Sirgy, 1985). This matching is also produced on SNS. For example, Kang et al. (2013) identified a positive relationship between SNS users with a high degree of SIC and continuance intentions and continued use. Therefore, different results may occur depending on the level of SIC. However, the literature examining the moderating effects of SIC in consumer behavior on SNS is scarce, and no studies have been reported within the context of clothing brands' SNS pages. Accordingly, we aim to answer the following research question:

RQ2. Are there any differences in the relationships between attitude and SNS intention, between SNS intention and SNS use, and between SNS use and purchase intentions among the users of clothing brands' SNS according to their different levels of selfimage congruity?

This study aims to help expand the explanatory power of TPB among users of clothing brands' SNS pages by incorporating the motivational factors of U\&G theory as an antecedent. This incorporation is based on the fact that Ajzen (1991) assumes that intentions capture the motivational factors of an individual, which in turn influence behavior. Furthermore, the moderating effect of SIC attempts to shed light on how self-image congruity may moderate attitudinal and behavioral factors among users of clothing brands' SNS pages. 
Consequently, the purpose of this study is: i) to apply U\&G, the TPB, and SIC to explain SNS users' intentions to purchase through clothing brands' SNS pages; ii) to examine the relationship between U\&G and attitude, SNS intentions, and SNS use among users of clothing brands' SNS; iii) to identify the influence of the three main factors of TPB on SNS intentions to use, of intentions to use on actual SNS use, of SNS use on purchase intentions, and of perceived behavioral control on the use of clothing brands' SNS; iv) to analyze the moderating effects of SIC between the attitudinal and behavioral activity of the users of clothing brands' SNS; and v) to test the model on a sample of users of clothing brands' SNS pages.

\section{Literature review and hypotheses}

There is a substantial amount of previous research on SNS intentions or SNS use using the TPB, U\&G and SIC theories, as shown in the summary in Table I. However, unlike online shopping research, the research on purchase intentions through SNS remains scant in the SNS literature as shown in Table I. This paper defends the appropriateness of the U\&G, TPB, and SIC theories as a conceptual framework to explain purchase intentions through SNS use.

\section{Table I}

Previous research on SNS use and SNS use+purchase using TPB, U\&G and SIC theories

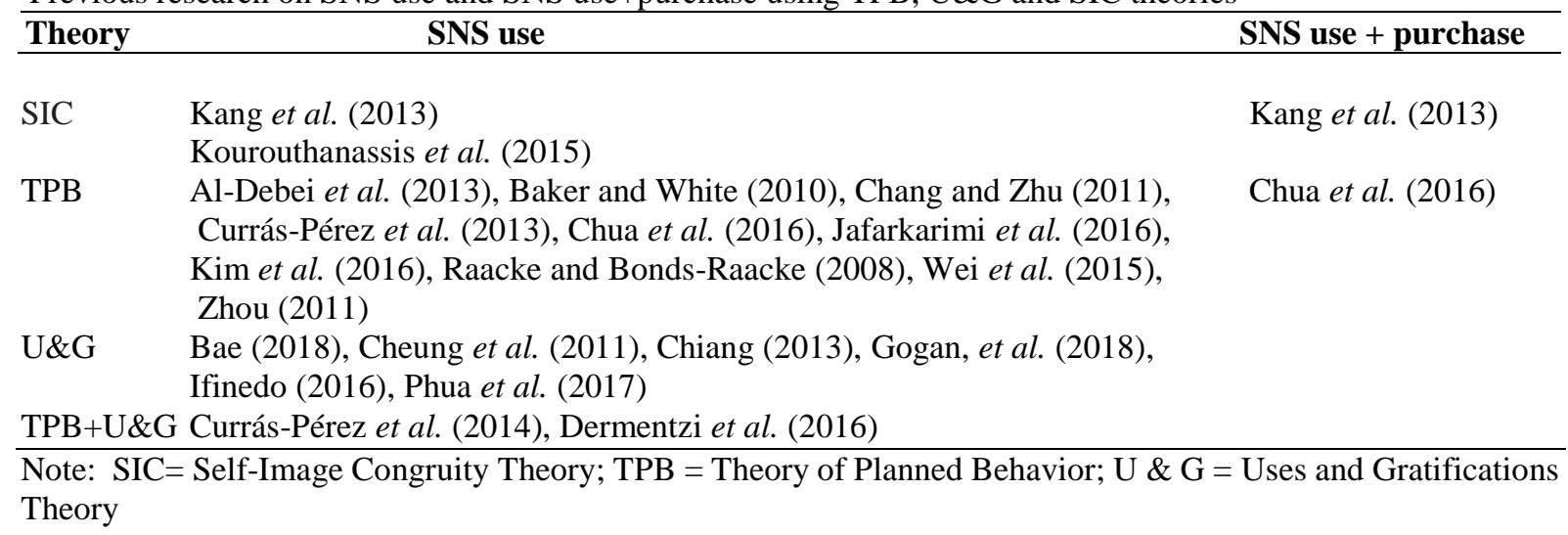

\section{Uses-and-Gratifications Theory $(U \& G)$}

U\&G theory explains the social and psychological needs that motivate an individual to select media channels and to choose content (Ruggiero, 2000). This satisfaction is itself a strong 
motivator to use these technologies recurrently (Bryant and Miron, 2004). U\&G posits that, through the consumption of different types of media, consumers of those media seek to satisfy their needs regarding information, socialization, entertainment, and escapism (LaRose and Eastin, 2004).

SNS, as a medium, should have behavioral gratifications similar to those obtained from the traditional mass media. When users' gratifications from using media are satisfied, they will develop a positive attitude toward them, which in turn influences the behavior that leads to continued use of media (Xu et al., 2012).

Previous research on online and SNS environments proposes several dimensions to analyze $\mathrm{U} \& \mathrm{G}$, depending on the context in which the research is conducted. Ji and Wayne Fu (2013) selected information, interaction, and access to identify their influence on a given user's affinity to the Internet. Xu et al. (2012) identified affection, coordination, immediate access, and leisure. Chiang (2013) found informativeness, social interactivity, and playfulness among Facebook users. Mäntymäki and Riemer (2014) identified hedonic outcomes and social presence as gratifications for users of the Habbo social networking game. Li et al. (2015) found enjoyment, fantasy, escapism, and achievement among users of a social network game. Kang and Johnson (2015) found that socialization and information seeking influence online social shopping intention among Facebook users. Ifinedo (2016) established self-discovery, entertainment, interpersonal connectivity, and social enhancement as gratifications among students who were users of SNS. Luo et al. (2011) used information seeking, entertainment, and interpersonal utility in an experiment about online newspapers. In sum, researchers chose the dimensions of gratifications that were best suited to the problem at hand, and most authors did not analyze U\&G even as a second-order variable, but instead focused on analyzing the effect of each dimension of $U \& G$. 
SNS users can enhance their knowledge of clothing brands through learning about new events, share information with the firm and their acquaintances, and feel they are in contact with their favorite clothing brand. Because it takes into account the clothing brand context, this research is based on four dimensions of gratification: 1) information seeking - the need individuals have to enhance their awareness and knowledge about themselves, others, and the whole world (Shao, 2009); 2) affection - the need to fulfill one's need for attachment (Luo et al., 2011); 3) social presence - the extent to which mass communication allows users to connect with others, experience others, and feel a sense of human contact through that medium (Xu et al. 2012); and lastly, 4) leisure - the search for entertainment or relaxation (Xu et al., 2012).

Consumers play an active role in the selection of media, and their motivations to use any kind of media depend on the gratifications that they feel when they use them (Katz et al., 1973). Therefore, the U\&G of any media usage is likely to influence the user's attitude toward each medium that he or she has decided to consume. Within the context of SNS, the literature has found a direct and positive relationship between $U \& G$ and attitude in the use of mobile SNS media in South Korea (Han et al., 2015 ), and in the intention to visit Facebook among Taiwanese users (Wei et al., 2015), but not in the clothing brand SNS context. Gratification is therefore expected to play a positive role in the formation of attitudes toward the SNS of clothing brands. Hence, the following hypothesis is proposed:

H1: U\&G has a positive effect on attitude toward using clothing brands' SNS pages.

Previous research offers evidence regarding the influence of $U \& G$ on the behavioral intention or intention to participate in SNS. Cheung et al. (2011) found a positive relationship between $U \& G$ and intention to use Facebook among members of online social groups, most of whom were students. Ku et al. (2013) provided evidence that gratifications are an antecedent of intentions to use SNS among college students from Taiwan. Mäntymäki and Riemer (2014) reported the influence of social presence and hedonic outcomes as a significant gratification on 
continuous use intentions among users of the German portal Habbo Hotel, one of the largest social virtual worlds for teenagers. Hsu et al. (2015) and Ifinedo (2016) identified a positive relationship between $\mathrm{U} \& \mathrm{G}$ and behavioral intentions to use SNS among international surfers of Facebook and among students from the Americas, respectively. Based on these empirical findings, individuals who obtain gratifications from using the SNS pages of a clothing brand are expected to show intentions to use it. Thus, the following hypothesis is proposed:

H2: U\&G has a positive effect on a user's intention to use clothing brands' SNS pages.

As discussed above, most SNS research has related the effect of gratifications to intentions to use, but relatively little research has been carried out with the aim of understanding the influence of gratifications on use or continuous use. Xu et al. (2012), however, developed a model in which gratifications were positively and directly related to use, following evidence from previous studies in the website context (Luo et al., 2011). Xu et al. (2012) identified a direct and positive effect of certain gratifications, such as coordination, immediate access, affection and leisure, on SNS usage among American students attending US universities.

In line with the foregoing information, we contend that users' gratifications from using clothing brands' SNS pages will be positively associated with intentions to use and to use not only when the population is made up of surfers, students or teenagers, but also when it consists of potential consumers of clothing brands. That is, the greater the gratifications a user obtains from using the SNS pages of a clothing brand are, the more likely he or she is to continue using an SNS. Therefore, we expect the following hypothesis to hold:

H3: U\&G has a positive effect on the use of a clothing brand's SNS pages.

Theory of Planned Behavior (TPB) 
TPB, originally postulated by Ajzen (1991), is an extension of the Theory of Reasoned Action (TRA) (Fishbein and Ajzen, 1975). TPB is a widely used framework for predicting the relationship between an individual's beliefs, intentions, and behavior through three different determinants: subjective norm (SN), attitude, and perceived behavioral control (PBC).

SN refers to the social impact that influences behavior, and reveals individuals' beliefs about how they would be viewed by others (that is, by their reference groups) if they performed a particular behavior (Fishbein and Ajzen, 1975). Previous literature has found a positive relationship between SN and intention to use Facebook (Al Debei et al., 2013; Baker and White, 2010; Hsu et al. 2014; Tariq et al., 2017; Wu et al., 2014), intention to follow brands on Twitter (Chu et al., 2016), and selfie-posting intentions (Kim et al., 2016). Focusing on fashion products, Cho and Yang (2012) identified SN as one of the predictors of attitude toward purchasing through SNS. The above literature suggests that individuals who comply with their reference groups tend to have intentions to participate on SNS. This leads to the following hypothesis:

H4: SN toward using SNS has a positive effect on intention to use clothing brands' SNS pages.

Attitude is a function of cognitive beliefs and indicates a positive or negative feeling about performing a specific behavior (Fishbein and Ajzen, 1975). Alarcón-del-Amo et al. (2014), Al Debei et al. (2013), Baker and White (2010), Hsu et al. (2014), Ruiz-Mafe et al. (2014), and Tariq et al. (2017) have found that there is a significant effect between attitude and intention to use SNS. In addition, this positive relationship was also found among users who follow brands on Twitter (Chu et al., 2016), and among users with intentions to post selfies on Instagram (Kim et al., 2016). Therefore, and based on these empirical studies, these relationships are also 
expected to occur within the context of the SNS of clothing brands. Thus, the following hypothesis is proposed:

H5: Attitude toward using SNS has a positive effect on intention to use clothing brands' SNS pages.

PBC is the individual's perceptions of their internal and external constraints to carry out a given behavior, and their capabilities to engage in this particular behavior (Ajzen, 1991). Prior research on SNS identified a significant influence of PBC on SNS intentions, such as Al Debei et al. (2013) and Tariq et al. (2017) among Facebook users, as well as among users who follow brands on Twitter (Chu et al., 2016), or among users who post material on Instagram (Kim et al., 2016). Within the SNS context, users' control over the use of clothing brands' SNS pages would be related to the personal control of frequency, continuance usage, and socializing during visits. Thus, the stronger their perceived control is, the more likely they are to show their intention to use the clothing brands' SNS pages. This leads to the following hypothesis:

H6: PBC over using an SNS has a positive effect on intention to use clothing brands' SNS pages.

PBC infers actual behavior when individuals are positive on assessing the skills, resources, and prerequisites they need to carry out a particular behavior (Ajzen, 1991). So, the higher the belief that one has the ability to carry out the behavior is, the greater the likelihood of actually performing the behavior will be. However, while the TPB literature also considers the relationship between PBC and actual behavior (Ajzen, 1991), few studies have been conducted to test this relationship within the context of SNS and results to date have been contradictory. 
For example, Baker and White (2010) and Al-Debei et al. (2013) did not find this relationship. In contrast, Zhao et al. (2016) found a direct and positive relationship between PBC and use, but within the context of social media users' rumor combating behavior. Accordingly, users will be more interested in using SNS if they have the resources, skills, and control to do so, together with the perception of control over clothing brands' SNS pages. Thus, the following hypothesis is proposed:

H7: PBC has a direct and positive effect on the use of clothing brands' SNS pages.

\section{Intention to use SNS}

The relationship between intention to use and actual use is part of the TPB model, which also contemplates a direct link between intention and behavior (Ajzen, 1991). This connection between intention to use and use is also tested among students in the literature on SNS (Al Debei et al., 2013; Kang et al., 2013). Nevertheless, this relationship has not been specifically verified within the context of the SNS pages of clothing brands. These previous findings suggest the predictive power of use intentions in the use of clothing brands' SNS pages. Hence, the greater a user's intention to use a clothing brand's SNS pages is, the more likely he or she is to make continuous use of these SNS. Thus, we propose the following hypothesis:

H8: Intention to use clothing brands' SNS pages has a direct and positive effect on the use of these SNS.

\section{SNS use}

Previous literature has found that retailers with active SNS are able to attract consumers to their brand's SNS page, and, through their SNS, they can get consumers to visit their brand website and increase their willingness to purchase products (Zhang et al., 2017). However, only a limited amount of research, such as the study by Pöyry et al. (2013), has identified the influence 
of use on the purchase intentions in the SNS context. These authors found a direct relationship between browsing the Facebook community of a European travel agency and intentions to purchase package holidays to popular destinations in Europe. Given that browsing involves the use of an SNS, we posit that this relationship will have a similar effect on the users of clothing brands' SNS pages, such that a greater level of SNS use will affect the purchase intentions of those users. Thus, the following hypothesis is proposed:

H9: The use of clothing brands' SNS pages has a direct and positive effect on users' purchase intentions.

\section{The moderating effects of self-image congruity (SIC)}

Self-congruity theory asserts that the behavior of a person, as a consumer, is in part determined by the comparison made between their self-image and the brands they are consuming (Sirgy et al., 1997). This comparison makes consumers prefer products related to their self-image (Sirgy and Samil, 1985). The literature has measured SIC as a multidimensional construct made up of a personal dimension - ideal self-image and actual self-image - and dimensions perceived by others, that is, social self-image and ideal social self-image (Sirgy, 1982). Previous research has provided more evidence of the effect of ideal and actual self-image on attitudinal variables than social and ideal social self-image (Jeong and Jang, 2018). Ideal self-image refers to how individuals would like to see themselves, and actual self-image refers to how individuals really perceive themselves (Sirgy, 1982). Actual self-image is the dimension used in this study, as other authors have done in the retail and SNS context (O'Cass and Grace, 2008; Kang et al., 2009; Kourouthanassis et al., 2015).

Clothing is a product category where purchases are made on a frequent basis to replace worn out clothes, to keep up with changing fashions, or to add to the consumer's wardrobe, and thus to have a wider assortment of clothes. This makes clothing different from other products 
because not everyone can afford items in other product categories. Furthermore, clothing is always on public display, and is one of the easiest ways of broadcasting one's self-image to others (Millan and Mittal, 2017).

Previous studies provide evidence supporting the influence of SIC on the consumer's experience (Hosany and Martin, 2012), attitude (Ibrahim and Najjar, 2008), and brand loyalty (Kressmann et al., 2006). Kang et al. (2009) found a positive and direct influence of self-image on continued online service usage intention among Cyworld users. Conversely, other researchers have found no evidence of a relationship between actual self-image and attitudinal variables, as is the case of the study by Jeong and Jang (2018), in which they did not identify any significant results between actual self-image and positive affection among customers of Fine-dine restaurants.

Additionally, the consumer behavior literature has studied the moderator effects of SIC. O'Cass and Grace (2008) established that the relation between store service and value was more significant between consumers with a high SIC. Kleijnen et al. (2005) also found that consumers with high image congruence presented a better attitude and intentions to adopt wireless services than those who experienced low image congruence. In contrast, and depending on the product or service, self-image congruity is less relevant. For example, Su and Reynolds (2017) found that business travelers, unlike those travelling for leisure purposes, base their hotel brand choices to a greater extent on hotel functionality than on self-image congruity. Furthermore publicly consumed brands, such as clothing brands, can be used by individuals as a tool to satisfy a person's reason for self-esteem, which implies the consumers' tendency to improve their self-esteem by reaching their ideal state. This means that for consumers of clothing products with a high self-image congruity the attitude toward a brand will be shown more by the ideal self-image than by the actual self-image (Hong and Zinkhan, 1995; Sirgy et $a l ., 2000)$. However, few studies in the SNS literature have analyzed the moderating effects of 
SIC. In one of them, Kourouthanassis et al. (2015), contrary to the findings of direct effects by Kleijnen et al. (2005), recognized a weak moderating effect in the relationship between attitudinal satisfaction (Liao et al., 2007) and continuance intention among low-SIC Facebook users. Therefore, if the purchasers of brands that are consumed publicly, such as clothing brands, with a more powerful self-image tend to reflect their ideal self-image more than the actual selfimage and previous research has found a weak moderating effect among low-SIC Facebook users, we could hypothesize that the moderating effect of SIC (actual self-image) between attitude and intentions to use clothing brands' SNS will be more significant for consumers with a low SIC than for those that have a high SIC. Thus, the following hypothesis is formulated:

H10. The positive relationship between attitude and intention to use clothing brands' SNS pages is stronger for low-SIC users than for high-SIC users.

Furthermore, SIC has been identified as a predictor of brand loyalty in the consumer literature (Kressmann et al., 2006). In fact, these authors show that the greater the self-image congruity with a brand is, the greater brand loyalty will be. Kang et al. (2013) found a positive relationship between SIC and both continuance intention and continued use among SNS users in Korea. Hence, and since SIC has been identified as a predictor of loyalty, the effect is expected to be the opposite of that included in the previous hypothesis; that is, the influence of SNS intentions on SNS use is stronger in users with high SIC than in users with low SIC. Based on this discussion, the following hypothesis is proposed:

H11. The positive relationship between SNS intentions and use of clothing brands' SNS pages is stronger for high-SIC users than for low-SIC users. 
In a study of consumption products, Ericksen (1996) identified a positive relationship between SIC and intention to purchase an American car among European consumers. Further studies confirmed this relationship, for example, in the purchase of team-licensed merchandise among fans of a sports team (Kwak and Kang, 2009). Hence, it is assumed that the greater selfcongruity is, the greater the purchase intentions will be. There is also expected to be a similar effect within the context of SNS. Consequently, the influence of SNS use on purchase intentions may be stronger in users with high SIC than in users with low SIC. In this regard, the following hypothesis is proposed:

H12. The positive relationship between SNS use and the purchase intentions of the users of clothing brands' SNS pages is stronger for high-SIC users than for low-SIC users.

A summary of the hypotheses is highlighted in Table II. The research model proposed in Figure 1 outlines all the hypotheses discussed in this paper.

\section{Table II}

Hypotheses summary

\begin{tabular}{ll}
\hline $\begin{array}{l}\text { Hypothesis } \\
\text { number }\end{array}$ & Hypotheses \\
\hline H1 & U\&G has a positive effect on attitude toward using clothing brands' SNS pages. \\
H2 & U\&G has a positive effect on a user's intention to use clothing brand's SNS pages. \\
H3 & U\&G has a positive effect on the use of a clothing brand's SNS pages. \\
H4 & SN toward using SNS has a positive effect on intention to use clothing brands' SNS pages. \\
H5 & Attitude toward using SNS has a positive effect on intention to use clothing brands' SNS pages. \\
H6 & PBC over using an SNS has a positive effect on intention to use clothing brands' SNS pages. \\
H7 & PBC has a direct and positive effect on the use of clothing brands' SNS pages. \\
H8 & Intention to use clothing brands' SNS pages has a direct and positive effect on the use of these SNS. \\
H9 & The use of clothing brands' SNS pages has a direct and positive effect on users' purchase intentions. \\
H10 & The positive relationship between attitude and intention to use clothing brands' SNS pages is \\
& stronger for low-SIC users than for high-SIC users.
\end{tabular}



for high-SIC users than for low-SIC users.

H12 The positive relationship between SNS use and the purchase intentions of the users of clothing brands' SNS pages is stronger for high-SIC users than for low-SIC users.

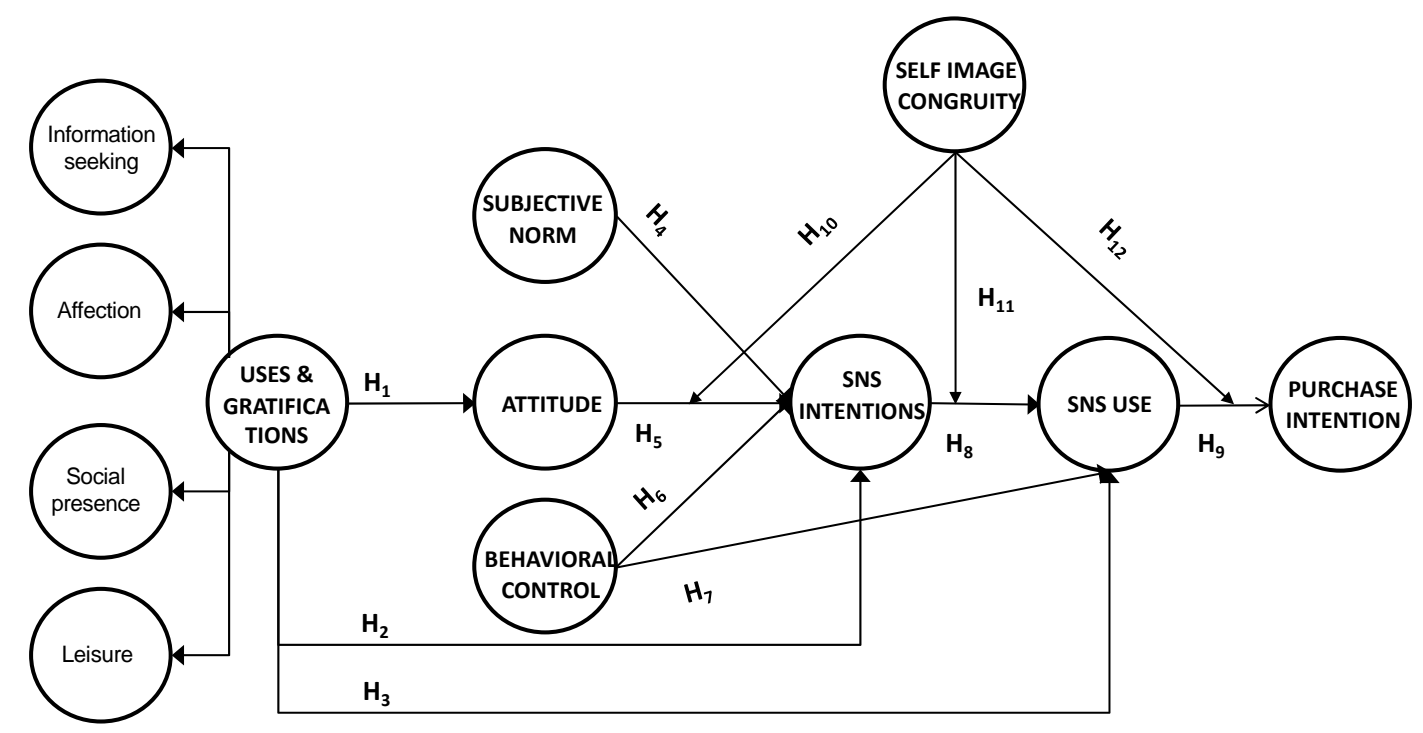

Fig. 1. Research model

\section{Methodology}

\section{Instrument}

The questionnaire is based on the literature review. U\&G was operationalized with four dimensions: Information seeking, affection, social presence, and leisure. Information seeking was adapted from the study by Park et al. (2009) and is composed of three items. Four items about affection were derived from $\mathrm{Xu}$ et al. (2012). Social presence was based on four items from Cheung et al. (2011). Leisure was built using five items from Xu et al. (2012). 
Subjective norm was built upon five items, three from the study by Mäntymäki et al. (2014), and two from Chiang (2013). Attitude was based on three items taken from Al Debei et al. (2013), and one item from the study by Baker and White (2010). Perceived behavioral control was composed of four items, three of which came from Al Debei et al. (2013), and one adapted from Mäntymäki et al. (2014). Intention to use SNS was based on three items extracted from Al Debei et al. (2013). SNS use is represented by one item adapted from Escobar-Rodríguez and Carvajal-Trujillo (2014). Purchase intention was assessed by two items based on the work of Tsai and Huang (2007). Finally, self-image congruity was measured by three items from Kang et al. (2013), and one from Lee and Jeong (2014).

The items were reviewed by holding qualitative interviews with academics, researchers, and professionals involved in online retail, who were asked whether the contents of the questionnaire were appropriate for the aims of the research. The results of the qualitative interviews led to some adjustments in several items of the questionnaire in order to make it easier for the interviewees to understand them. Additionally, to test the first draft and the items, a pilot test with 90 individual questionnaires was carried out between October and November 2015 with undergraduate students, allowing for a first run-through of the model robustness and scale validation.

The final items of the questionnaire were evaluated on a seven-point Likert scale ranging from 1 (= strongly disagree) to 7 (= strongly agree).

\section{Sampling}

Surveys were collected using Netquest (netquest.com), an independent online provider of data for market research in Spain with a panel of more than 200,000 Spanish consumers. Sampling followed a non-probability method because only people using social networks to visit the pages of their favorite clothing brands, and with ages ranging between 18 and 44 years old, were 
selected. Older adults were not selected because the largest concentration of non-users of social networks is to be found in those who are over 45 years of age (IAB, 2016). Of the 2,653 initial responses, and after applying the exclusion criteria (incomplete, dubious, outside age limits), 1,003 questionnaires were available for statistical analysis. Of the participants, $19 \%$ were male and $81 \%$ were female, with ages ranging from 18 to 44 years old. Most of them were university graduates $(88 \%)$. More than $63 \%$ of the respondents used Facebook to reach their clothing brand pages, $23 \%$ used Instagram, and the remaining $14 \%$ was made up of those who use Twitter, Pinterest, and others. Finally, the four most cited favorite brands were Zara (14\%), Stradivarius (7\%), Nike (5\%), and Desigual (5\%). Table III shows the demographic characteristics.

\section{Method of analysis}

Data analysis was performed using structural equation modeling (SEM) to test hypotheses 1 through 9, while hypotheses 10 through 12 were tested using multi-group SEM analysis.

SEM offers the possibility of simultaneously estimating all the relationships proposed in the theoretical conceptual model, thereby achieving a complete representation of this model (BouLlusar et al., 2009). Furthermore, SEM allows for the introduction of latent variables that can only be measured through observable variables (Bou-Llusar et al., 2009), such as the dimensions of TPB and U\&G. The common way to test moderating effects is to split the data set into two or more groups (low, medium, and high SIC) and to compare the model fit across

\section{Table III}

Demographic characteristics

\begin{tabular}{|c|c|c|c|}
\hline Measure & Item & Frequency & $\%$ \\
\hline \multirow[t]{2}{*}{ Gender } & Male & 190 & $19 \%$ \\
\hline & Female & 813 & $81 \%$ \\
\hline \multirow[t]{3}{*}{ Age } & $18-24$ & 274 & $27 \%$ \\
\hline & $25-34$ & 401 & $40 \%$ \\
\hline & $35-44$ & 333 & $33 \%$ \\
\hline \multirow{2}{*}{ Education background } & High School & 118 & $12 \%$ \\
\hline & University Degree & 885 & $88 \%$ \\
\hline \multirow[t]{3}{*}{ Occupation } & Enterprise employee and & & \\
\hline & Civil servant & 542 & $54 \%$ \\
\hline & Student & 236 & $24 \%$ \\
\hline
\end{tabular}




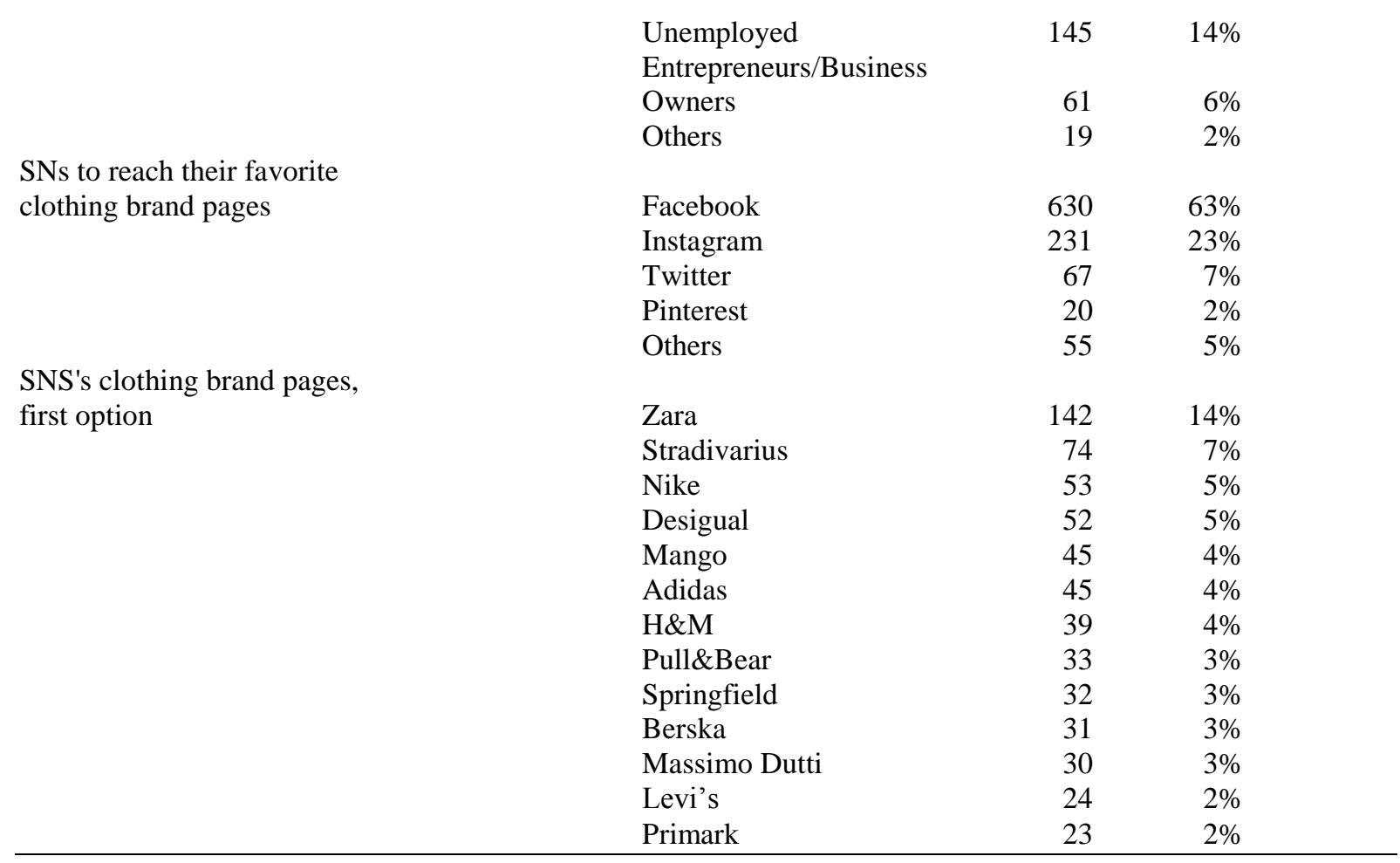

groups (Im et al., 2008). The models were estimated from the matrices of variances and covariances by the maximum likelihood procedure with EQS 6.1 (Bentler, 2006).

Two stages were used to ensure that all criteria have the characteristics required to validate the scale. First, to avoid a complex model and prior to primary data analysis, the U\&G scale was operationalized through a composite measure (Landis et al., 2000), also referred to as item parceling (Bandalos and Finney, 2001). Consequently, a study of the dimensionality, reliability, and validity of the U\&G scale was carried out with a confirmatory factor analysis (CFA) to ensure that the construct that we intended to measure has actually been measured, to refine the scale, and to remove non-significant items. In the case of $U \& G$, the items sharing the same dimension were averaged to form composite measures (Bandalos and Finney, 2001; Bou-Llusar et al., 2009). Composite measures are combinations of items that create score aggregates which are then subjected to a second CFA, together with the rest of the scales considered in the study, with the aim of validating them. In CFA, the use of composite measures is helpful for two 
reasons: it enables us to better meet the normal distribution assumption of maximum likelihood estimation, and it results in more parsimonious models because it reduces the number of variances and covariances to be estimated. Consequently, the stability of the parameter estimates increases, the variable-to-sample-size ratio improves, and the impact of sampling error on the estimation process is reduced (Bandalos and Finney, 2001). Thus, the results discarded the leisure dimension, and there were finally three dimensions (information seeking, affection, and social presence), with a total of 11 items.

A composite measure of each dimension of $U \& G$ was introduced as an indicator variable in the analyses conducted to assess the dimensionality, reliability, and validity of the scales.

In the second stage, the dimensionality, reliability, and validity of the total scale of the structural model were studied by means of another CFA, and the discriminant validity of the scales associated with the model was also tested. Finally, the invariance of the instrument of measurement (full scale) was tested in order to compare the regression coefficients of each of the three samples (SIC moderator effect).

\section{Findings}

\section{Validation of scales and Invariance test}

The first phase of the analysis was focused on the psychometric properties of the U\&G scale for the whole sample (Table IV). The probability associated with chi-squared reaches a value higher than 0.05 (0.05137), indicating a good overall fit of the scale (Jöreskog and Sörbom, 1996). Convergent validity is demonstrated in two ways. First, the factor loadings are significant and greater than 0.5 (Bagozzi and $\mathrm{Yi}, 1988$ ). Second, the average variance extracted (AVE) for each of the factors is higher than 0.5 (Fornell and Larcker, 1981), ranging from 0.60 (information seeking) to 0.84 (affection). The reliability of the scale is demonstrated by the composite reliability indices obtained for each of the dimensions, which are higher than 0.6 
(Bagozzi and Yi, 1988), with levels that ranged from 0.77 (information seeking) to 0.95

(affection).

Table IV

Analysis of the dimensionality, reliability and validity ot he U\&G scale (fully standardized solution)

\begin{tabular}{|c|c|c|c|}
\hline Uses and Gratifications (U\&G) & F. loading & $\mathrm{t}$ & source \\
\hline \multicolumn{4}{|l|}{ Information Seeking $(\mathrm{AVE}=0.60 ; \mathrm{CR}=0.77)$} \\
\hline \multicolumn{4}{|l|}{ I visit my favorite clothing brands in SNS: } \\
\hline To learn about new events & 0.68 & $9.80 * *$ & \multirow{3}{*}{$\begin{array}{l}\text { Park et al. } \\
\quad(2009)\end{array}$} \\
\hline To contribute to a pool of information & 0.76 & $9.87 * *$ & \\
\hline To provide others with information & 0.75 & $10.49 * *$ & \\
\hline \multicolumn{4}{|l|}{ Affection $(\mathrm{AVE}=0.84 ; \mathrm{CR}=0.95)$} \\
\hline When visiting my favorite clothing's brand page in SNS: & & & \multirow{5}{*}{$\begin{array}{l}\text { Xu et al. } \\
\text { (2012) }\end{array}$} \\
\hline I like to socialize to show others I care about their feelings & 0.88 & $11.13 * *$ & \\
\hline I like to socialize to show others encouragement & 0.93 & $11.11 * *$ & \\
\hline I like to socialize to help others & 0.91 & $11.10 * *$ & \\
\hline I like to socialize because I'm concerned about others & 0.92 & $10.99 * *$ & \\
\hline \multicolumn{4}{|l|}{ Social presence $(\mathrm{AVE}=0.78 ; \mathrm{CR}=0.92)$} \\
\hline \multicolumn{4}{|l|}{ There is a sense of: } \\
\hline Human contact in my favorite clothing's brand page in SNS & 0.90 & $15.08 * *$ & \multirow{4}{*}{$\begin{array}{l}\text { Cheung et } \\
\text { al. (2011) }\end{array}$} \\
\hline Sociability in my favorite clothing's brand page in SNS & 0.89 & $14.77 * *$ & \\
\hline Warmth in my favorite clothing's brand page in SNS & 0.89 & $12.44 * *$ & \\
\hline Human sensitivity in my favorite clothing's brand page in SNS & 0.78 & $14.82 * *$ & \\
\hline
\end{tabular}

Notes: Fit of the model: chi-square $(\chi 2)=48.4656, \mathrm{df}=34, \mathrm{p}=0.05137$; root mean square error of approximation $(\mathrm{RMSEA})=0.021$; Bentler-Bonett non-normed fit index $(\mathrm{NNFI})=0.997$; comparative fit index $(\mathrm{CFI})=0.998 ; \mathrm{CR}=$ composite reliability; $\mathrm{AVE}=$ average variance extracted; $* * \mathrm{p}<.01$.

The discriminant validity of a construct, evaluated through AVE (Fornell and Lacker, 1981), states that a construct must share more variance with its indicators than with other constructs in the model. This occurs when the square root of the AVE between each pair of factors is higher than the estimated correlation between those factors, as occurs here, thereby ratifying its discriminant validity (Table V).

Table V

Discriminant validity of the U\&G scale

\begin{tabular}{lccc}
\hline & Information seeking & Affection & Social presence \\
\hline Information seeking & 0.77 & & \\
Affection & $0.60^{* *}$ & 0.92 & 0.88 \\
Social presence & $0.60^{* *}$ & $0.54^{* *}$ & \\
\hline
\end{tabular}

Notes. Below the diagonal: estimated correlation between the factors extracted; $* * p<.01$. 
To statistically test the differential effects regarding the SIC between high, medium, and low groups, a four-item scale, based on the research by Kang et al. (2013) and Lee and Jeong (2014), was used: 'Using SNS to visit my favorite clothing brand's page helps to maintain my image and character', 'Using SNS to visit my favorite clothing brand's page reflects who I am', 'Using SNS to visit my favorite clothing brand's page fits my image well', and 'People using SNS to visit their favorite clothing brand's page are similar to me'. This scale was submitted to a CFI and one factor was obtained (factor loadings were greater than 0.70; $\mathrm{CR}=0.89 ; \mathrm{AVE}=$ 0.72), the model presented adequate fit as the probability associated with $\chi^{2}$ was greater than 0.05 (0.284). A cluster analysis was carried out to obtain different groups with different levels of SIC, forming a hierarchical cluster. Once the cluster centers were obtained, a k-means cluster analysis was applied, resulting in three groups with different levels of SIC: high level (values between 5.04 and 5.81), 311 individuals; medium level (values between 3.96 and 4.12), 357; and low level (values between 1.51 and 2.17), 335 .

Furthermore, the invariance of the factor loadings regarding the different levels of U\&G was ratified (Table VI). It is thus possible to compare the estimated composite measure parameters as input (Satorra and Bentler, 2010). The steps of the process used to ratify the partial invariance are as follows: (i) the model considered individually for each of the three samples fits well (separately) in all three: low $\left(\chi^{2}=35.540 ; \mathrm{df}=34\right)$; medium $\left(\chi^{2}=44.527\right.$; df =34), and high $\left(\chi^{2}=40.151\right.$; df $\left.=34\right)$; (ii) simultaneous estimation of the model in the three samples, to verify that the number of factors is the same, and again the model also works adequately $\left(\chi^{2=} 120.219\right.$; $\left.\mathrm{df}=102\right)$; and (iii) the metrical invariance proves the equality of the factor loadings in the three groups. When this restriction is introduced into the model, it is observed that the model fit is not significantly different from what is shown previously in step 2 , as we can deduct from a comparison between the $\chi^{2}$ of steps 2 and $3\left(\Delta \chi^{2}=19.340 ; \Delta \mathrm{df}=20\right.$; $\mathrm{p}=0.160>0.05$ ), so the invariance of the factor loadings is confirmed. 
Table VI

Invariance measurement test for $\mathrm{U} \& \mathrm{G}$.

\begin{tabular}{|c|c|c|c|c|c|c|c|c|c|}
\hline & $\chi^{2}$ & df & $\Delta \chi^{2}$ & $\Delta \mathbf{d f}$ & $\mathbf{p}$ & RMSEA $(90 \%$ CI) & SRMR & CFI & NNFI \\
\hline \multicolumn{10}{|l|}{ Individual groups } \\
\hline Low & 35.540 & 34 & & & & $0.012(0.000-0.042)$ & 0.037 & 0.999 & 0.999 \\
\hline Medium & 44.527 & 34 & & & & $0.028(0.000-0.048)$ & 0.064 & 0.994 & 0.990 \\
\hline High & 40.151 & 34 & & & & $0.026(0.000-0.054)$ & 0.049 & 0.996 & 0.994 \\
\hline \multicolumn{10}{|c|}{ Measurement of invariance: } \\
\hline Simultaneous model & 120.219 & 102 & & & & $0.021(0.000-0.054)$ & 0.076 & 0.997 & 0.995 \\
\hline $\begin{array}{l}\text { Model with restricted } \\
\text { factor loadings }\end{array}$ & 139.560 & 124 & 19.340 & 22 & 0.160 & $0.019(0.000-0.034)$ & 0.070 & 0.997 & 0.996 \\
\hline
\end{tabular}

Once composite measures have been formed from the items sharing the same dimension in the $U \& G$ scale, the psychometric properties of the scales forming the model were analyzed (Bandalos and Finney, 2001) (Table VII).

With those composite measures of $U \& G$ and the other dimensions of the model, the psychometric properties of the model for the whole sample were analyzed with a CFA. From this CFA, six dimensions were used: U\&G, SN, attitude, PBC, SNS intention, and purchase intention. The probability associated with chi-squared reaches a value higher than $0.05(0.227)$, indicating a good overall fit of the scale (Jöreskog and Sörbom, 1996). Convergent validity is demonstrated because the factor loadings are significant and higher than 0.5 , and the AVE for each of the factors is higher than 0.5 (AVE ranged from 0.51 (U\&G) to 0.83 (purchase intention). As for the reliability of the scale, the indices of the composite reliability of each of the dimensions obtained are higher than 0.6, with levels that ranged from 0.74 (SNS use) to 0.93 (subjective norm).

\section{Table VII}

Analysis of the dimensionality, reliability and validity of the scales of measurement (Fully standardized solution)

\begin{tabular}{lccc}
\hline Constructs & $\begin{array}{c}\text { Factor } \\
\text { Loading }\end{array}$ & t & Source \\
\hline U\&G (AVE= 0.51; CR= 0.76) & & & \\
Information Seeking & 0.75 & $25.31^{* *}$ & Composite \\
Affection & 0.70 & $21.61^{* *}$ & measures \\
Social Presence & 0.69 & $21.19^{* *}$ & \\
\hline
\end{tabular}




\begin{tabular}{|c|c|c|c|}
\hline \multicolumn{4}{|l|}{$\mathrm{SN}(\mathrm{AVE}=0.72 ; \mathrm{CR}=0.93)$} \\
\hline \multicolumn{4}{|l|}{ People who influence my behavior: } \\
\hline Encourage me to participate in my favorite clothing's brand SNS & 0.91 & $33.71 * *$ & \multirow{3}{*}{$\begin{array}{l}\text { Mäntymäki et } \\
\text { al. (2014) }\end{array}$} \\
\hline Think I should continue using SNS to visit my favorite clothing's brand SNS & 0.73 & $22.87 * *$ & \\
\hline People who are important to me: & & & \\
\hline Would think I should continue using SNS to visit my favorite clothing's brand & 0.82 & $28.35 * *$ & \multirow{3}{*}{ Chiang (2013) } \\
\hline Use SNS to visit their favorite clothing's brand page & 0.86 & $29.55 * *$ & \\
\hline Think that I should participate in my favorite clothing's brand page & 0.90 & $32.38 * *$ & \\
\hline \multicolumn{4}{|l|}{ Attitude $(\mathrm{AVE}=.70 ; \mathrm{CR}=.90)$} \\
\hline I have a positive opinion about my favorite clothing's brand page in SNS & 0.74 & $21.99 * *$ & \multirow{3}{*}{$\begin{array}{l}\text { Al Debei et } \\
\text { al. } \\
(2013)\end{array}$} \\
\hline I think continuance in visiting my favorite SNS clothing's brand is good to me & 0.86 & $30.21 * *$ & \\
\hline $\begin{array}{l}\text { I think continuance in visiting my favorite SNS clothing's brand is appropriate to } \\
\text { me }\end{array}$ & 0.90 & $31.76 * *$ & \\
\hline I find pleasant to visit my favorite clothing's brand page in SNS & 0.83 & $24.46 * *$ & $\begin{array}{l}\text { Baker and } \\
\text { White (2010) }\end{array}$ \\
\hline \multicolumn{4}{|l|}{$\operatorname{PBC}(\mathrm{AVE}=0.64 ; \mathrm{CR}=0.88)$} \\
\hline $\begin{array}{l}\text { I feel I have personal control over continuance usage of SNS to visit my favorite } \\
\text { clothing's brand page }\end{array}$ & 0.68 & $20.17 * *$ & \multirow[t]{3}{*}{$\begin{array}{l}\text { Al Debei et } \\
\text { al. }(2013)\end{array}$} \\
\hline $\begin{array}{l}\text { The frequency in I will continue using SNS to visit my favorite clothing's brand } \\
\text { page it is under my control }\end{array}$ & 0.84 & $26.33 * *$ & \\
\hline $\begin{array}{l}\text { Whether or not I continue use SNS to visit my favorite clothing's brand page is } \\
\text { entirely up to me }\end{array}$ & 0.84 & $23.69 * *$ & \\
\hline $\begin{array}{l}\text { I have complete control over whether I could socialize on SNS when visiting my } \\
\text { favorite clothing's brand page }\end{array}$ & 0.83 & $26.07 * *$ & $\begin{array}{l}\text { Mäntymäki et } \\
\text { al. (2014) }\end{array}$ \\
\hline \multicolumn{4}{|l|}{ SNS intention $(\mathrm{AVE}=0.79 ; \mathrm{CR}=0.92)$} \\
\hline I intend using SNS to visit my favorite clothing's brand page in the future & 0.87 & $30.48 * *$ & \multirow{3}{*}{$\begin{array}{l}\text { Al Debei et } \\
\text { al. } \\
(2013)\end{array}$} \\
\hline I will continue using SNS to visit my favorite clothing's brand page in the future & 0.91 & $34.50 * *$ & \\
\hline $\begin{array}{l}\text { I will regularly use SNS to visit my favorite clothing's brand page in the future } \\
\text { SNS use (AVE }=\mathbf{0 . 7 4 ;} \mathbf{C R}=\mathbf{0 . 7 4})\end{array}$ & 0.88 & $32.47 * *$ & \\
\hline How much time did you spend in your favorite brand's page in each visit & 0.86 & $28.32 * *$ & $\begin{array}{c}\text { Escobar- } \\
\text { Rodríguez et } \\
\text { al (2014) }\end{array}$ \\
\hline $\begin{array}{l}\text { Purchase intention (AVE= } \mathbf{0 . 8 3} ; \mathbf{C R}=\mathbf{0 . 9 1} \text { ) } \\
\text { I consider myself as loyal patron of my favorite clothing brands while visiting it's } \\
\text { page in the SNS } \\
\text { I consider to buy through SNS page of my favorite clothing brands page as my } \\
\text { first choice }\end{array}$ & 0.87 & $27.57 * *$ & $\begin{array}{l}\text { Tsai \& Huang } \\
(2007)\end{array}$ \\
\hline
\end{tabular}

Notes. Fit of the model: chi-square $(\chi 2)=199.0793, \mathrm{df}=185, \mathrm{p}=0.22704 ;$ RMSEA $=0.009 ; \mathrm{NNFI}=0.998$; $\mathrm{CFI}=0.999 ; * * \mathrm{p}<.01$

Table VIII shows the results of discriminant validity evaluated through AVE. The square roots of the AVE were greater than the correlations among the constructs, thus supporting the discriminant validity of all the constructs.

Table VIII

Discriminant validity of the scales associated with the model.

\begin{tabular}{llllllll}
\hline & $\mathbf{1}$ & $\mathbf{2}$ & $\mathbf{3}$ & $\mathbf{4}$ & $\mathbf{5}$ & $\mathbf{6}$ & $\mathbf{7}$ \\
\hline U\&G & 0.71 & & & & & & \\
SN & $0.65^{* *}$ & 0.85 & & & & & \\
Attitude & $0.50^{* *}$ & $0.60^{* *}$ & 0.83 & & & & \\
PBC & $-0.07 \mathrm{~ns}$ & $0.08^{* *}$ & $0.35^{* *}$ & 0.80 & & & \\
\hline
\end{tabular}




\begin{tabular}{|c|c|c|c|c|c|c|c|}
\hline SNS intention & $0.41 * *$ & $0.40 * *$ & $0.51 * *$ & $0.43 * *$ & 0.89 & & \\
\hline SNS use (behavior) & $0.28 * *$ & $0.27 * *$ & $0.25^{* *}$ & $0.02 \mathrm{~ns}$ & $0.19 * *$ & 0.86 & \\
\hline Purchase intention & $0.34 * *$ & $0.41 * *$ & $0.61 * *$ & $0.51 * *$ & $0.67 * *$ & $0.21 * *$ & 0.91 \\
\hline
\end{tabular}

Notes. Below the diagonal: estimated correlation between the factors; $* *_{p}<.01 ; * \mathrm{p}<.05$

The invariance test should precede the verification of the differences in the parameters that are common to the study variables among the three groups considered (low, medium, high) (Byrne, 2006) (Table IX). Taking into account the same considerations as in the preceding invariance test, the invariance of the factor loadings is ratified, as deduced from the comparison between the $\chi^{2}$ of steps 2 and $3\left(\Delta \chi^{2}=35.320 ; \Delta d f=44 ; p=0.821>0.05\right)$.

\section{Table IX}

Invariance measurement test all scales.

\begin{tabular}{|c|c|c|c|c|c|c|c|c|c|}
\hline & $\chi^{2}$ & df & $\Delta \chi^{2}$ & $\Delta \mathbf{d f}$ & $\mathbf{p}$ & RMSEA (90\% CI) & SRMR & CFI & NNFI \\
\hline \multicolumn{10}{|l|}{ Individual groups } \\
\hline Low & 221.434 & 185 & & & & $0.024(0.002-0.032)$ & 0.070 & 0.988 & 0.985 \\
\hline Medium & 218.138 & 185 & & & & $0.021(0.000-0.048)$ & 0.072 & 0.990 & 0.987 \\
\hline High & 201.615 & 185 & & & & $0.018(0.000-0.034)$ & 0.082 & 0.993 & 0.991 \\
\hline \multicolumn{10}{|c|}{ Measurement of invariance: } \\
\hline Simultaneous model & 641.187 & 555 & & & & $0.023(0.014-0.030)$ & 0.074 & 0.989 & 0.986 \\
\hline $\begin{array}{l}\text { Model with restricted } \\
\text { factor loadings }\end{array}$ & 676.508 & 599 & 35.320 & 44 & 0.821 & $0.020(0.009-0.027)$ & 0.076 & 0.991 & 0.990 \\
\hline
\end{tabular}

\section{Structural model results}

The results of the model fit test indicated that the probability of the chi-squared is higher than 0.05 (0.088), CFI (0.997) is close to unity, and RMSEA is close to zero (0.012). Additionally, the variance in attitude $\left(R^{2}=0.445\right)$ was explained by $U \& G$. The variance in intentions $\left(R^{2}=\right.$ 0.376) was described by $\mathrm{SN}$, attitude, $\mathrm{PBC}$, and $\mathrm{U} \& \mathrm{G}$. The variance in SNS use $\left(\mathrm{R}^{2}=0.896\right)$ was explained by intentions, $\mathrm{PBC}$, and $\mathrm{U} \& \mathrm{G}$. Finally, the variance in purchase intentions $\left(\mathrm{R}^{2}\right.$ $=0.501$ ) was explained by SNS use. This indicates that the model in this study does successfully predict and explain the variance in the dependent variables. 
The result of the analysis shows that all relationships proposed in the model are supported. Therefore, $U \& G$ is an antecedent of attitude $(\mathrm{H} 1)(\beta=0.61, p<0.01)$, and at the same time is directly related to SNS intentions $(\mathrm{H} 2)(\beta=0.10, \mathrm{p}<0.01)$, and SNS use $(\mathrm{H} 3)(\beta=0.42$, $\mathrm{p}<0.01)$. SN is an antecedent of SNS intentions $(\mathrm{H} 4)(\beta=0.61, \mathrm{p}<0.01)$. Attitude is a precursor of SNS intentions $(\mathrm{H} 5)(\beta=0.40, \mathrm{p}<0.01)$. PBC proves to be a predecessor of SNS intentions (H6) $(\beta=0.40, p<0.01)$, as well as of SNS use $(\mathrm{H} 7)(\beta=0.23, \mathrm{p}<0.01)$. SNS intentions is an originator of SNS use (H8) $(\beta=0.64, p<0.01)$. Finally, SNS use is a clear precursor of purchase intention (H9) $(\beta=0.71, \mathrm{p}<0.01)$ (Table $\mathrm{X}$ and Figure 2).

\section{Table X}

Structural model relationships obtained.

\begin{tabular}{llrr}
\hline Hypothesis & Path & Parameter & t \\
\hline H1 & U\&G $\rightarrow$ attitude & 0.61 & $14.61^{* *}$ \\
H2 & U\&G $\rightarrow$ SNS intentions & 0.10 & $4.68^{* *}$ \\
H3 & U\&G $\rightarrow$ SNS use & 0.42 & $4.25^{* *}$ \\
H4 & SN $\rightarrow$ SNS intentions & 0.10 & $4.68^{* *}$ \\
H5 & Attitude $\rightarrow$ SNS intentions & 0.40 & $8.26^{* *}$ \\
H6 & PBC $\rightarrow$ SNS intentions & 0.40 & $9.90^{* *}$ \\
H7 & PBC $\rightarrow$ SNS use & 0.23 & $3.28^{* *}$ \\
H8 & SNS intentions $\rightarrow$ SNS use & 0.64 & $5.13^{* *}$ \\
H9 & SNS use $\rightarrow$ purchase intention & 0.71 & $5.18^{* *}$ \\
\hline
\end{tabular}

Notes. Fit of the model: chi-square $(\chi 2)=224.3, \mathrm{df}=197, \mathrm{p}=0.088 ; \mathrm{RMSEA}=0.012 ; \mathrm{NNFI}=0.997$; CFI $=$ $0.997 ; * * \mathrm{p}<.01$

\section{Moderating effects results}

The existence of significant differences in the hypothesized relationships was estimated in order to analyze the moderating effect exercised by the different levels of self-image 


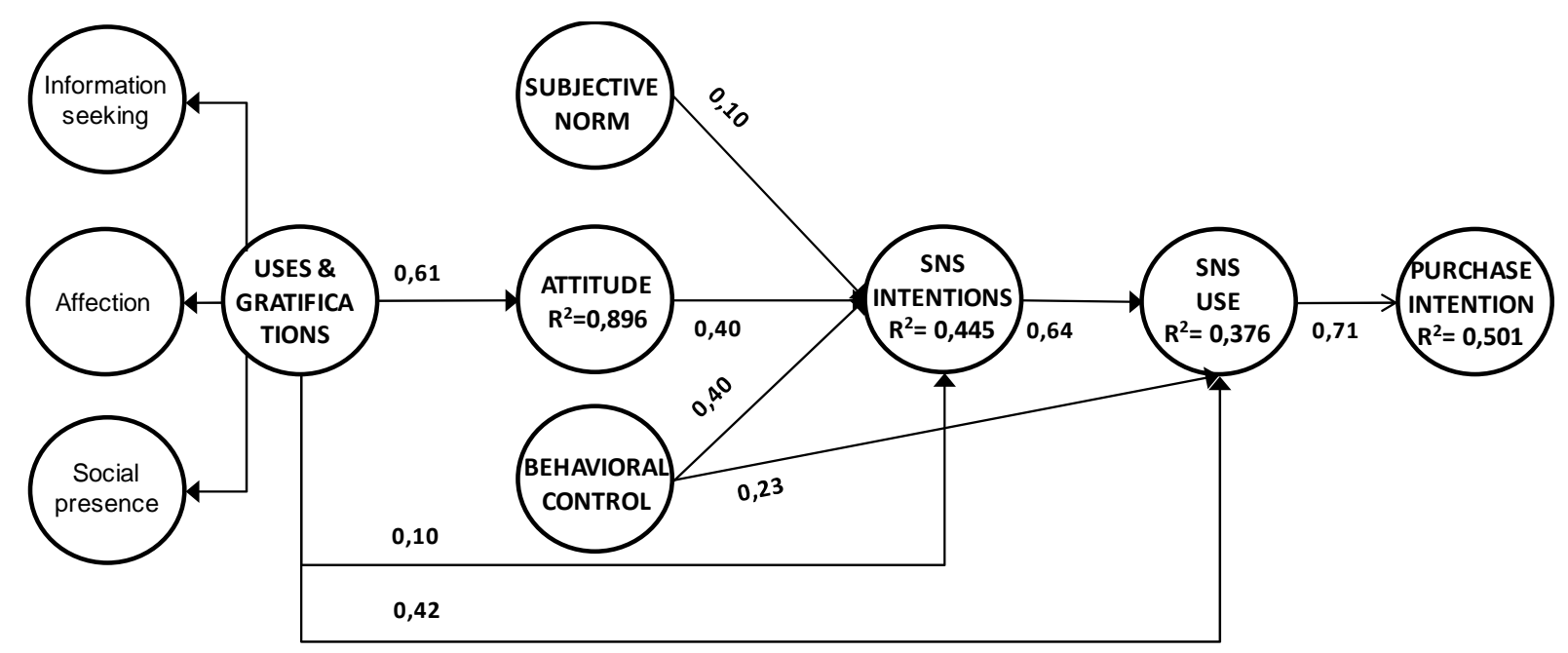

Fig.2. Results of the proposed research model

congruity. Restrictions were added to allow calculation of these significant differences between the parameters estimated by comparing the $\chi^{2}$ of the restricted structural model with the $\chi^{2}$ of the unrestricted structural model. The results show that the degree of SIC moderates some relationships in the model (Table XI and Figure 3).

Thus, SIC exerts more influence between attitude and SNS intentions for the sample of users of clothing brands' SNS pages with medium SIC than those with high SIC $\left(0.40\right.$ and $0.21, \Delta \chi^{2}$ =7.330; $\mathrm{p}=0.007<0.05$ ), thereby supporting $\mathrm{H} 10$.

SIC exerts more influence between SNS intentions and SNS use in the sample of users of clothing brands' SNS pages with high SIC than those with medium SIC $\left(0.64\right.$ and $0.59, \Delta \chi^{2}$ $=5.164 ; \mathrm{p}=0.023<0.05)$. SIC was found to exert more influence in the relationships among SNS intentions and SNS use for the sample of users of clothing brands' SNS pages with medium SIC than those with low $\operatorname{SIC}\left(0.59\right.$ and $\left.0.43, \Delta \chi^{2}=4.083 ; \mathrm{p}=0.043<0.05\right)$. These results provide support for H11.

SIC exerts more influence between SNS use and purchase intentions in the sample of users of clothing brand pages with low SIC than medium-SIC users $\left(0.94\right.$ and $0.70, \Delta \chi^{2}=4.035$; $\mathrm{p}=0.045<0.05)$. Furthermore, SIC exerts more influence on the sample of users of clothing 
brand pages with low SIC than on those with high SIC $\left(0.94\right.$ and $0.63, \Delta \chi^{2}=4.364 ; p=0.037<$

0.05). Although there are differences between the SIC groups in this relationship, the results have gone in the opposite direction. Thus, H12 is rejected (Table XI and Figure 3).

\section{Table XI}

The moderating effects of Self-image congruity relationships obtained.

\begin{tabular}{|c|c|c|c|c|c|c|c|c|c|c|c|c|c|}
\hline \multirow[b]{2}{*}{ Нур } & \multirow[b]{2}{*}{ Path. } & \multicolumn{2}{|c|}{$\mathbf{L}$} & \multicolumn{2}{|c|}{$\mathbf{M}$} & \multicolumn{2}{|c|}{$\mathbf{H}$} & \multicolumn{2}{|c|}{ L-M } & \multicolumn{2}{|c|}{ L-H } & \multicolumn{2}{|c|}{ H-M } \\
\hline & & Par. & $\mathbf{t}$ & Par. & $\mathbf{t}$ & Par. & $\mathbf{t}$ & $\Delta \chi^{2}$ & $\mathbf{p}$ & $\Delta \chi^{2}$ & $\mathbf{p}$ & $\Delta \chi^{2}$ & $\mathbf{p}$ \\
\hline H10 & Attitude $\rightarrow$ SNS Intentions & 0.45 & $4.94 * *$ & 0.40 & $4.81^{* *}$ & 0.21 & $2.66^{* *}$ & 0.477 & $0.490(\mathrm{~ns})$ & 7.078 & $0.008 * *$ & 7.330 & $0.007 * *$ \\
\hline H11 & SNS Intentions $\rightarrow$ SNS Use & 0.43 & $2.24 *$ & 0.59 & $2.91 * *$ & 0.64 & $2.28 *$ & 4.083 & $0.043 *$ & 5.164 & $0.023 *$ & 0.466 & 0.495 (ns) \\
\hline H12 & SNS Use $\rightarrow$ Purchase Intention & 0.94 & $2.48 *$ & 0.70 & $2.95^{* *}$ & 0.63 & $2.63 * *$ & 4.035 & $0.045^{*}$ & 4.364 & $0.037 *$ & 2.382 & $0.123(\mathrm{~ns})$ \\
\hline
\end{tabular}

Hyp. = Hypothesis; Par. =Parameter; L= Low; M= Medium: H=High; (ns) =Not significant. Notes. Fit of the model: chisquare $(\chi 2)=651.732, \mathrm{df}=618, \mathrm{p}=0.168 ; \mathrm{RMSEA}=0.013 ; \mathrm{NNFI}=0.996 ; \mathrm{CFI}=0.996 ; * * \mathrm{p}<.01 ; * \mathrm{p}<.05 ; \mathrm{ns}=\mathrm{no}$ significant; Simultaneously latent variables test: $\Delta \chi 2=22.386 ; \Delta \mathrm{df}=6 ; \mathrm{p}=0.001<0.05$

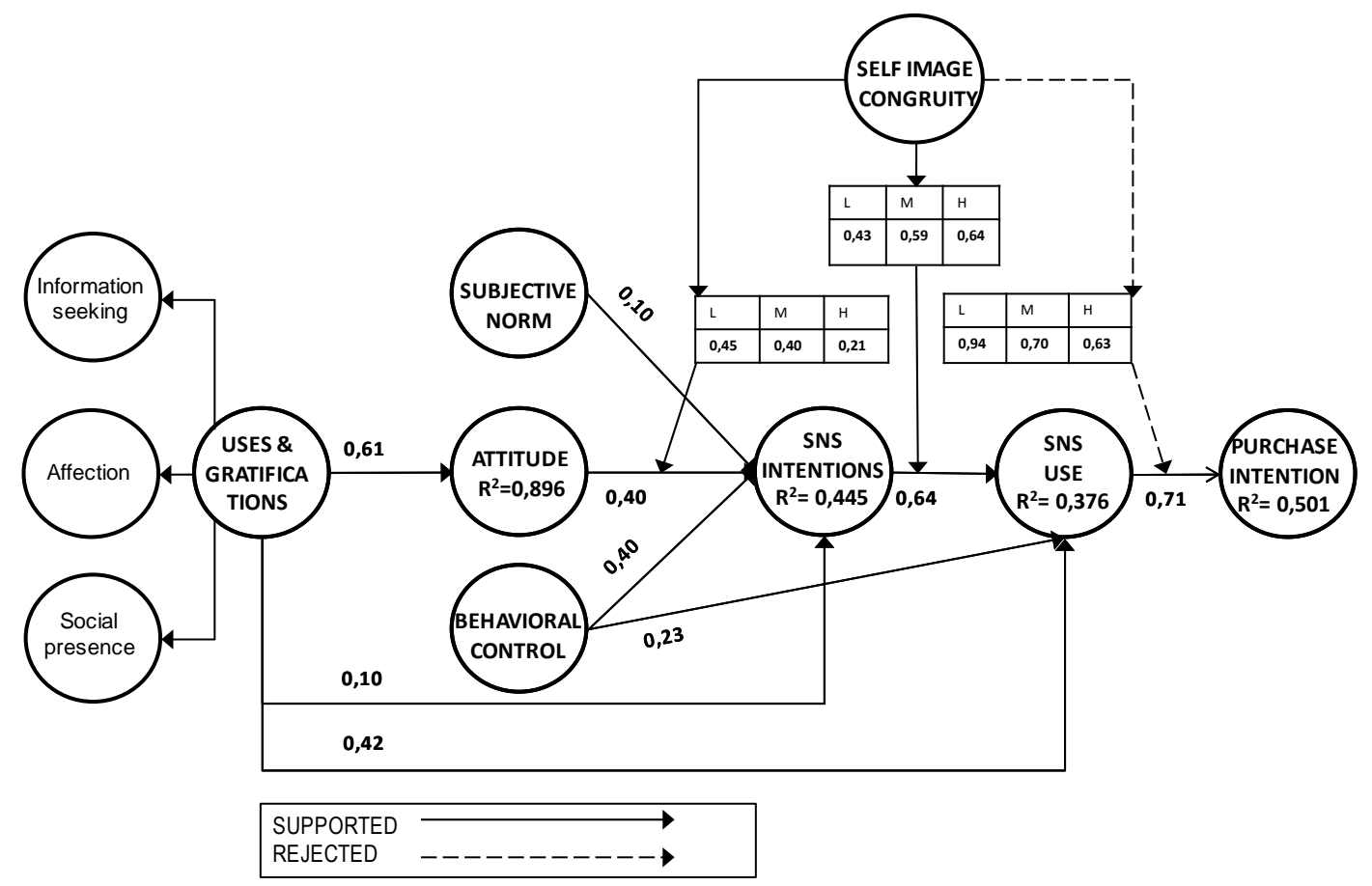

Fig. 3. Results for the proposed research model including moderator effects

Additionally, a multi-group analysis was performed to determine whether the higher proportion of females in the sample might influence the results. The findings reveal that there 
are no significant differences in any of the relationships hypothesized in the model. In all cases, the probabilities associated with chi-squared reach values higher than 0.09 , and therefore exceed the limit value of 0.05 , below which there are significant differences. Likewise, a global analysis of all the parameters was performed. This analysis showed an increase in the chisquared and in the degrees of freedom of 9.86 and 9, respectively, with an associated probability of 0.36219 , which determines the absence of significant differences due to gender in the causal relationships proposed in the model.

\section{Discussion}

This study seeks to integrate the U\&G and TPB theories and the moderating effects of SIC in order to understand the factors influencing consumers' intention to purchase clothing through SNS. The results of the analysis of the data collected provide evidence supporting the relationships proposed in the conceptual framework. Furthermore, our empirical findings reveal that the role of SIC is significant as a moderating effect.

The influence of U\&G on attitude is consistent with earlier literature on SNS (Wei et al., 2015), and partially with Ha et al. (2015), because they hypothesize each of the dimensions of U\&G individually. These authors found a direct and positive relationship between integrative (affection) and hedonic gratifications and attitude, and a positive and indirect relationship between the social interactive dimension, through the integrative dimension, and attitude. They also identified the influence of cognitive (information) and social gratifications on attitude as a non-significant relationship. One possible explanation for this is that the study by Ha et al. (2015) is based on the use of mobile Facebook and KakaoTalk for entertainment purposes. The specific characteristics of mobile devices, and their small screens, do not offer favorable conditions to search for information as on other devices, such as laptops or tablets. Accordingly, it is reasonable to think that users of these devices seek more hedonic gratifications. In contrast, 
utilitarian gratifications, such as information seeking, are more appropriate in the context of clothing brands, where information about the brand is sought and shared.

Based on existing literature, U\&G were set as antecedents of SNS intentions. It was proven empirically that U\&G exert a direct effect on SNS intentions, which is consistent with previous studies (Ku et al., 2013). However, consistency with the previous literature depends on the dimensions of U\&G that each of the authors has used. For example, the results are consistent in social presence (Mäntymäki and Riemer, 2014), in information seeking and social presence (Hsu et al., 2015), and in social presence and interpersonal interactivity (affection) (Cheung et al., 2011; Ifinedo, 2016). These results could be interpreted as meaning that information gratification is a significant dimension among more utilitarian users, such as the users of clothing brands' SNS pages, in contrast to other studies involving samples of students or teenagers, in which this gratification is not significant (Cheung et al., 2011; Ifinedo, 2016; Mäntymäki and Riemer, 2014). These findings support the fact that users of clothing brands' SNS pages use SNS to seek information about the brand, for sociability, and to have human contact on the clothing brands' SNS pages. These findings suggest that U\&G are critical to ensure users continue to browse on the clothing brands' SNS pages, and could explain why these users prefer to have immediate gratifications and novelty (Lay, 2018).

This study has demonstrated that there is a strong relationship between U\&G and SNS use, and this positive impact is stronger than the influence of U\&G on SNS intentions, which corroborates an earlier SNS study where affection and social presence gratifications affect SNS use (Xu et al., 2012). This indicates that gratifications such as information seeking, affection, and social presence may help explain the reasons why clothing brands' SNS pages are gratifiers that encourage the use of SNS, taking into account that all members of the sample are users of these SNS. So, for these users intention to use is less relevant than actual use. 
The empirical results of this research revealed that SN, attitude, and PBC positively predicted SNS intentions. In particular, both attitude and PBC were found to be strongly related to SNS intentions. These findings are consistent with previous studies in the SNS context, which reported that subjective norm, attitude, and $\mathrm{PBC}$ have a positive influence on intentions (Al Debei et al., 2013; Baker and White, 2010; Chu et al., 2016; Kim et al., 2016; Mäntymäki et al., 2014). Contrary to other studies of SNS (Al Debei et al., 2013; Baker and White, 2010; Kim et al., 2016; Mäntymäki et al., 2014), the effect of SN on SNS intentions is much lower than that of attitude and PBC $(\beta=0.10)$. One possible explanation could be that users are in a technology post-adoption era and have enough experience with it for SN to lose importance in favor of attitude and PBC. The positive relationship between PBC and SNS intentions contradicts the study by Curras-Perez et al. (2014), who did not find this relationship to be significant among users of friend social networks. Furthermore, the positive and direct relationship between PBC and SNS use corroborates the study by Zhao et al. (2016), based on rumor combating on social media, but contradicts the results of Al Debei et al. (2013) and Baker and White (2010), who found this relationship to be non-significant in their study of Facebook users in Jordan, and Australian SNS users, respectively. In sum, these findings indicate that PBC plays an important role in SNS intentions and the use of clothing brands' SNS pages. The positive relationship between PBC and SNS intentions and SNS use suggests that users of clothing brands' SNS pages, unlike what happens in the case of the contents of other social networks, need great control over the system even though they know that the social networks of clothing brands are used on a voluntary basis.

The direct and positive influence of intention to engage in SNS use is coherent with other previous studies in the SNS field (Al Debei et al., 2013; Kang et al., 2013). Finally, the findings show a direct and positive relationship between SNS use and purchase intention, which establishes a novel theoretical contribution within the context of customers who use an SNS to 
visit clothing brands' sites. One possible explanation is that the general attractiveness of social SNS, and more specifically likes, posts and images, predispose favorably toward the purchase of the product. Another explanation could refer to the changes in the habits and information search systems of clothing brand consumers (PwC, 2018), taking into account that the majority of clothing consumers use digital channels before, during or after making their purchases (Lay, 2018). This influence is consistent with the study by Zhang et al. (2017), which posits that continuous exposure to SNS reduces the search and information costs, thereby increasing the possibilities of purchase.

The findings of this research reveal that SIC moderates the effect of attitude on SNS intentions, the effect of SNS intentions on SNS use, and the influence of SNS use on purchase intention, and thus make a contribution to the SNS literature, specifically within the context of clothing brands. These results extend the existing SNS literature by showing that low and medium SIC exert a greater impact between attitude and SNS intention, and between SNS use and purchase intentions, while high and medium SIC have a greater impact between SNS intentions and SNS use.

More specifically, first, attitude is more important for the development of intentions to continue to use clothing brands' SNS pages for users who reported low and medium SIC toward their favorite clothing brands' SNS than for those who expressed high SIC. These results are in line with Hong and Zinkhan (1995) and Sirgy et al. (2000), who posited that for consumers with high SIC, ideal SIC could be more crucial than actual SIC when they purchase brands to be used publicly. Thus, these results would show that in the context of this research, which is that of clothing brand products that are consumed to be shown in public, actual SIC is more relevant for users with a low SIC than for those with a high SIC. This is reflected in the fact that low-SIC users show a greater influence of attitude on intention to use clothing brands' SNS pages, which is a contribution of this research. Second, the impact of SNS intentions on SNS 
use of clothing brands' pages is more significant for users who reported high and medium SIC than for those who showed low SIC. According to these outcomes, users' SIC facilitates continuous SNS usage. Once the intention to visit a clothing brand's page through SNS has been established, it is found that the more prominent their SIC is, the more likely a user is to engage in a certain behavior.

Third, the influence of SNS usage on purchase intentions is greater for users who reported low and medium SIC than for those who have expressed high SIC. These outcomes are the opposite of what was suggested in hypothesis H12. A possible explanation would be in line with the same one in $\mathrm{H} 10$ for the consumption of publicly brands, in which ideal SIC is more critical than actual SIC for high-SIC consumers. Another explanation would be that the fact that the first-choice brands of the respondents are low-cost may reflect the fact that congruence between actual self-image and clothing brands is less relevant for the use of the SNS to purchase products for users with higher levels of SIC.

\section{Theoretical contributions, implications, limitations, and future research}

This study provides several theoretical contributions and implications for research. First, it clarifies the mechanism underlying customers' intention to purchase through SNS from the perspective of the TPB and U\&G theories. The research model presented here details the entire path of SNS usage, from attitude, intention, and use through to purchase intention in the clothing brand context.

Second, this work is the first comprehensive study to interrelate the TPB and U\&G theories among clothing brand consumers in a technology post-adoption setting, such as that of clothing brands' pages on SNS. Therefore, the constructs of both theories significantly influence the formation of the purchase intention of users of clothing brands' SNS pages.

Third, unlike previous research on entertainment contexts, the study provides support for the key role of users' gratifications in attitude and the use of clothing brands' SNS pages and, 
more specifically, the information seeking dimension for utilitarian contexts such as clothing brands' SNS pages. The findings verify that U\&G are critical to keep users browsing the SNS pages of clothing brands.

Fourth, this study contributes to the theory of planned behavior by providing evidence of its efficacy in explaining behavior in intentions to purchase on the clothing brands' SNS pages. Nonetheless, efforts to test and support its efficacy in this context, as in this research, have been limited. The study also contributes by improving the predictive ability of TPB through the strong and positive relationship between PBC and SNS that previous authors had not highlighted as significant (Al Debei et al., 2013; Baker and White, 2010).

Fifth, this study confirms the existence of moderating effects of self-image congruity within the context of SNS, which has not been accomplished before, especially in the case of clothing brands' SNS pages. All self-image congruity groups (high, medium, and low) are excellent moderators to predict consumer behaviors through the SNS of clothing brands. Furthermore, although the literature regarding the moderating effects of SIC in the SNS context is limited, and these effects on the three groups are significant, one of the results is contrary to expectations, since it is the users with low SIC who have the strongest relationship between SNS use and purchase intentions. This finding could be explained by situational influence. Kleijnen et al. (2005) posited that the situational influence overrules the effect of low SIC. In the case of SNS, individuals share information and socialize with others. This situational fact could make the relationship between SNS use and purchase intentions stronger in the low-SIC users.

The results of this study suggest some implications for the community/marketing managers of clothing brands and retail companies. Individuals approach the SNS looking for what is entertaining or useful, yet the transition from participation to brand page visits and purchases is more complex, demanding other gratifications such as affection, socializing or information, as shown in this study. Consequently, clothing brands need to generate immediate 
gratifications, such as contents and events dealing with novelties, which engage users to better accomplish the transition from use to purchase. Further, taking into account the strong influence of PBC on SNS intentions, SNS intentions on SNS use, and SNS use on purchase intention, clothing brands have to better develop their SNS so that they facilitate access to all activities and contents in order to encourage continued use. This is essential in this context, in which the number of consumers who shop in digital environments and interact more with pre- and postpurchase actions on the SNS is increasing year after year. In this regard, the SNS offer great opportunities for clothing brands and, by extension for B2C companies, to better know consumers' needs, opinions and motivations, and additionally to strengthen their position as clothing brands (PwC, 2017). Consequently, they need to be able to organize their SNS bearing in mind consumer gratifications, in view of the influence of gratifications in the use of the SNS revealed by this study.

Additionally, and based on the groups resulting from the application of the moderating effect of SIC among clothing brand customers, marketers must be able to develop strategies to create more SNS brand beliefs, aiming mainly at the high-SIC group so as to improve their attitude and SNS use. To do so, clothing brands could adjust the contents of their SNS to users' self-image congruence. For example, they could incorporate more tools that enable customized user-generated content to be developed on their Facebook or Instagram pages. Likewise, managers should develop strategies that improve self-image and reinforce the intentions of lowSIC users.

There are several limitations to this study. First, our data were obtained from a panel of people using social networks to visit the pages of their favorite clothing brands. This explains the differences between the numbers of females and males in the sample used in this study. Consequently, this fact may be a limitation when it comes to generalizing the findings. Second, the individuals' first-choice brand was low-cost. Accordingly, the results of the moderating 
effects of self-image congruity could be influenced by this bias. Third, while the survey sample is large, it consists of residents in a single country: Spain. Consequently, the results are inherent to Spanish culture and idiosyncrasy, and other nations and other cultures could offer different outcomes, limiting the potential generalizability of the conclusions presented here. It would thus be interesting to extend this research to other countries in order to test and confirm the model. Future research should also take into account individuals whose first-choice brand is situated in other quality-price segments in order to avoid the low-cost brand bias. Future research could measure the ideal dimension of SIC in order to test differences between actual and ideal SIC.

\section{References}

Ajzen, I. (1991) "The theory of planned behavior", Organizational Behavior Human Decission Processess, Vol. 50 No. 2, pp. 179-211.

Alarcón-del-Amo, M., Lorenzo-Romero, C. and Del Chiappa, G. (2014) "Adoption of social networking sites by Italian", Information Systems E-Business Management, Vol. 12, pp. 165-187.

Al-Debei, M.M., Al-Lozi, E. and Papazafeiropoulou, A. (2013) "Why people keep coming back to Facebook: explaining and predicting continuance participation from an extended theory of planned behaviour perspective", Decission Support Systems, Vol. 55 No. 1, pp. 43-54.

Bagozzi R.P. and Yi, Y. (1988) "On the evaluation of structural equation models", Journal of the Academy of Marketing Science, Vol. 16 No. 1, pp. 74-94.

Bae, M. (2018) "Understanding the effect of the discrepancy between sought and obtained gratification on social networking site users' satisfaction and continuance intention", Computers in Human Behavior. Vol. 79, pp. 137-153.

Baker R.K. and White K.M. (2010). Predicting adolescents' use of social networking sites from an extended theory of planned behaviour perspective. Computers in Human Behavior, Vol. 26 No. 6, pp. 1591-1597.

Bandalos D.L. and Finney, F.J. (2001) "Advanced structural equation modelling: new developments and techniques", in Marcoulides, G.A. and Schumacker, R.E. (Eds), Item parceling issues in structural equation modelling, Lawtence Erbaum, Mahwah, NJ, pp. 269-296.

Bentler, P. (2006), EQS structural equations program manual, Multivariate Software Inc., Encino, CA.

Bou-Llusar, J.C., Escrig-Tena, A.B., Roca-Puig, V. and Beltrán-Martí, I. (2009) “An empirical assessment of the EFQM Excellence Model: Evaluation as a TQM framework relative to the MBNQA Model", Journal of Operations Management, Vol. 27 No. 1, pp. 1-22.

Bryant J. and Miron, D. (2004) "Theory and research in mass communication", Journal of Communication, Vol. 54 No. 4, pp. 662-704. 
Byrne, B.M. (2006). Structural equation modeling with EQS: basic concepts, applications, and programming, Lawrence Erlbaum, Mahwah, NJ.

Chae, H. and Ko, E. (2016) "Customer social participation in the social networking services and its impact upon the customer equity of global fashion brands", Journal of Business Research, Vol. 69 No.9, pp. 3804-3812.

Chang, Y.P. and Zhou, D.H. (2011)" Understanding social networking sites adoption in China: A comparison of pre-adoption and post-adoption", Computers in Human Behavior, Vol. 27 No 5, pp. 1840-1848.

Cheung, C.M.K., Chiu, P-Y. and Lee, M.K.O. (2011) "Online social networks: why do students use facebook?”, Computers in Human Behavior, Vol. 27 No. 4, pp. 13371343.

Chiang, H-S. (2013) "Continuous usage of social networking sites", Online Information Review, Vol. 37 No. 6, pp. 851-871.

Cho, Y. and Yang, H. (2012) "The effect of characteristics in fashion social commerce sites and SNS subjective norm on consumer attitudes towards social commerce and purchase intention of fashion products", Journal of the Korean Society of Clothing and Textiles, Vol. 36 No. 11, pp. 1148-1161.

Chu, S-C., Chen, H-T. and Sung, Y. (2016) "Following brands on Twitter: an extension of theory of planned behavior", International Journal of Advertising, Vol. 35 No. 3, pp. 421-437.

Chua, S-C., Hsuan-Ting Chen, H-T. and Sung, Y. (2016) "Following brands on Twitter: an extension of theory of planned behavior", International Journal of Advertising, Vol. 35 No 3, pp. 421-437.

Currás-Pérez, R., Ruiz-Mafé, C. and Sanz-Blas, S. (2013) "Social network loyalty: evaluating the role of attitude, perceived risk and satisfaction", Online Information Review, Vol. 37 No 1, pp. 61-82.

Currás-Pérez, R., Ruiz-Mafe, C. and Sanz-Blas, S. (2014) "Determinants of user behavior and recommendation in social networks. An integrative approach from the uses and gratifications perspective", Industrial Management \& Data Systems, Vol. 114 No. 9, 1477-1498.

Dermentzi, E., Papagiannidis, S., Osorio Toro, C. and Yannopoulou, N. (2016) "Document academic engagement: differences between intention to adopt Social Networking Sites and other online technologies", Computers in Human Behavior, Vol. 61, pp. 321-332.

Dhir, A., Khalil, A., Lonka, K. and Tsai, C-C. (2017) "Do educational affordances and gratifications drive intensive Facebook use among adolescents?", Computers in Human Behavior, Vol. 68, March, pp. 40-50.

Ericksen, M.K. (1996) "Using self-congruity and ideal congruity to predict purchase intention: A European perspective", Journal of Euromarketing, Vol. 6 No. 1, pp. 41-56.

Escobar-Rodríguez, T. and Carvajal-Trujillo, E. (2014) "Online purchasing tickets for low cost carriers: an application of the unified theory of acceptance and use of technology (UTAUT) model", Tourism Management, Vol. 43, pp. 70-88.

Facebook (2018) Company Info | Facebook Newsroom. In: Facebook newsroom, available at: http://newsroom.fb.com/company-info/ (accessed February, 9, 2018).

Fishbein, M. and Ajzen, I. (1975), Belief, attitude, intention \& behavior, Addison Wesley, Reading, MA.

Fornell, C. and Lacker, D.F. (1981) "Evaluating structural equation models with unobservable variables and measurement error", Journal of Marketing Research, Vol. 18 No. 1, pp. 39-50. 
Gogan, I., Zhang, Z. and Matemba, E. (2018) "Impacts of gratifications on consumers' emotions and continuance use intention: an empirical study of Weibo in China", Sustainability, Vol. 10 No 9, pp. 3162. (1-20).

Haj-Salem, N., Chebat, J., Michon, R., and Oliveira, S. (2015) "Why male and female shoppers do not see mall loyalty through the same lens? The mediating role of self-congruity", Journal of Business Research, Vol. 69 No. 3, pp. 1219-1227.

Han, S., Min, J. and Lee, H. (2015) "Antecedents of social presence and gratification of social connection needs in SNS: A study of Twitter users and their mobile and non-mobile usage", International Journal of Information Management, Vol. 35 No. 4, pp. 459-471.

Hansen, J. M., Saridakis, G. and Benson, V. (2018) 'Risk, trust, and the interaction of perceived ease of use and behavioral control in predicting consumers' use of social media for transactions', Computers in Human Behavior, 80, pp. 197-206.

Hong, J.W and Zinkhan, G.M. (1995) "Self-concept and advertising effectiveness: The influence of congruency, conspicuousness, and response mode", Psychology and Marketing, Vol. 12 No 1, 53-77.

Hosany, S. and Martin, D. (2012) "Self-image congruence in consumer behavior", Journal of Business Research, Vol. 65 No. 5, pp. 685-691.

Hsu, C-L., Yu, C-C. and Wu, C-C. (2014) "Exploring the continuance intention of social networking websites: an empirical research", Information Systems EBusiness Management, Vol. 12 No. 2, pp. 139-163.

Hsu, M-H., Tien, S-W., Lin, H-C. and Chang, C-M. (2015) "Understanding the roles of cultural differences and socio-economic status in social media continuance intention", Information Technology \& People, Vol. 28 No. 1, pp. 234-241.

IAB Spain. 2016. Estudio Anual de Redes Sociales 2016. Madrid. http://iabspain.es/wp-

content/uploads/IAB_EstudioRedesSociales_2016_VCorta.pdf (January 31, 2017).

Ibrahim, H. and Najjar, F. (2008) "Assessing the effects of self-congruity, attitudes and customer satisfaction on customer behavioural intentions in retail environment", Marketing Intelligence \& Planning, Vol. 26 No. 2, pp. 207-227.

Ifinedo, P. (2016) "Applying uses and gratifications theory and social influence processes to understand students' pervasive adoption of social networking sites: perspectives from the Americas", International Journal of Information Management, Vol. 36 No. 2, pp. 192-206.

Im, I., Kim, Y. and Han, H-J. (2008) "The effects of perceived risk and technology type on users' acceptance of technologies", Information \& Management, Vol 45 No. 1, pp. 1-9.

Instagram (2018) "A quick walk through our history as a company", available at: https://instagram-press.com/our-story/ (accessed February, 9, 2018).

Jafarkarimi, H., Saadatdoost, R., Tze, A., Sim, H. and Hee, J. M. (2016) "Behavioral intention in social networking sites ethical dilemmas: An extended model based on Theory of Planned Behavior", Computers in Human Behavior, 62, pp. 545561.

Jeong, E. and Jang, S. (2018)" The affective psychological process of self-image congruity and its influences on dining experience", International Journal of Contemporary Hospitality Management, Vol. 30 No. 3, pp. 1563-1583.

Ji, P. and Wayne Fu, W. (2013) "Love Internet, love online content", Internet Research, Vol. 23 No. 4, pp. 396-413. 
Jöreskog, K.G. and Sörbom D. (1996), LISREL 8: User's reference guide, Scientific Software International, Chicago, IL.

Kang, J-Y.M. and Johnson, K.K.P. (2015) "F-Commerce platform for apparel online social shopping: Testing a Mowen's 3M model", International Journal of Information Management, Vol. 35 No.6, pp. 691-701.

Kang, Y.S., Hong, S. and Lee, H. (2009) "Exploring continued online service usage behavior: the roles of self-image congruity and regret", Computers in Human Behavior, Vol. 25 No.1, pp. 111-122.

Kang, Y.S., Min, J., Kim, J. and Lee, H. (2013) "Roles of alternative and self-oriented perspectives in the context of the continued use of social network sites", International Journal of Information Management, Vol. 33 No. 3, pp. 496-511.

Katz, E., Blumler, J.G. and Gurevitch, M. (1973) "Uses and gratifications research", Public Relations Opinion Quarterly, Vol. 37 No. 4, 509-523.

Kim, E., Lee, J-A., Sung, Y. and Choi, S.M. (2016) "Predicting selfie-posting behavior on social networking sites: an extension of theory of planned behavior", Computers in Human Behavior, Vol. 62, pp. 116-123.

Kleijnen, M., de Ruyter, K., and Andreassen, T.W. (2005) "Image congruence and the adoption of service innovations", Journal of Service Research, Vol. 7 No. 4, pp. 343-359.

Kourouthanassis, P., Lekakos, G. and Gerakis, V. (2015) "Should I stay or should I go? The moderating effect of self-image congruity and trust on social networking continued use", Behaviour and Information Technology, Vol. 34 No. 2, pp. 190203.

Kressmann, F., Sirgy, M. J., Herrmann, A., Huber, F., Huber, S. and Lee, D-J. (2006) "Direct and indirect effects of self-image congruence on brand loyalty", Joumal of Business Research, Vol. 59 No. 9, pp. 955-964.

$\mathrm{Ku}, \mathrm{Y}-\mathrm{C}$., Chen, R. and Zhang, H. (2013) "Why do users continue using social networking sites? An exploratory study of members in the United States and Taiwan", Information \& Management, Vol. 50 No. 7, pp. 571-581.

Kwak, D.H. and Kang, J-H. (2009) "Symbolic purchase in sport: the roles of self-image congruence and perceived quality", Managing Decision, Vol. 47 No. 1, pp. 85-99.

Landis, R.S., Beal, D.J. and Tesluk, P.E. (2000) "A comparison approaches to forming composite measures in structural equation models", Organizational Research Methods, Vol. 3 No. 2, pp. 186-207.

LaRose, R. and Eastin, M.S. (2004) "A social cognitive theory of Internet uses and gratifications: toward a new model of media attendance", Journal of Broadcasting \& Electronic Media, Vol. 48 No. 3, pp. 358-377.

Lay, R (2018) "Digital transformation - the ultimate challenge for the fashion industry", available at: https://www2.deloitte.com/ch/en/pages/consumer-industrialproducts/articles/ultimate-challenge-fashion-industry-digital-age.html (accessed February 2, 2018).

Lee, S and Jeong, M. (2014) "Enhancing online brand experiences: an application of congruity theory", International Journal Hospitality Management, Vol. 40 No. 1, pp. 49-58.

Li, H., Liu, Y., Xu, X., Heikkilä, J. and Van der Heijden, H.(2015) "Modeling hedonic is continuance through the uses and gratifications theory: an empirical study in online games", Computers in Human Behavior, Vol. 48, pp. 261-272.

Liao, C., Chen J-L. and Yen, D.C. (2007) "Theory of planning behavior (TPB) and customer satisfaction in the continued use of e-service: an integrated model", Computers in Human Behavior, Vol. 23 No. 6, pp. 2804-2822. 
Luo, M.M., Chea, S., Chen J-S. (2011) "Web-based information service adoption: a comparison of the motivational model and the uses and gratifications theory", Decision Support Systems, Vol. 51 No. 1, pp. 21-30.

Mango (2017a) In Facebook [Fan Page]. Retrieved from https://caes.facebook.com/mango.com/ (accessed January, 17, 2017).

Mango (2017b) In Instagram [Fan Page]. Retrieved from https://www.instagram.com/mango/ (accessed January, 17, 2017).

Mäntymäki, M., Merikivi, J., Verhagen, T., Feldberg, F. and Rajala, R. (2014) "Does a contextualized theory of planned behavior explain why teenagers stay in virtual worlds?", International Journal of Information Management, Vol. 34 No. 5, pp. 567-576.

Mäntymäki, M. and Riemer, K. (2014) "Digital natives in social virtual worlds: a multimethod study of gratifications and social influences in Habbo Hotel", International Journal of Information Management, Vol. 34 No. 2, pp. 210-220.

Millan, E. and Mittal, B. (2017) "Consumer preference for status symbolism of clothing: the case of the Czech Republic", Psychology \& Marketing. DOI: 10.1002/mar.20990.

O'Cass, A. and Grace, D. (2008) "Understanding the role of retail store service in light of self-image-store image congruence", Psychology \& Marketing, Vol. 25 No. 6, pp. 521-537.

Park, N., Kee, K.F. and Valenzuela, S. (2009) "Being immersed in social networking environment: Facebook groups, uses and gratifications, and social outcomes", Cyberpsychology and Behavior, Vol. 12 No. 6, pp. 729-733.

Phua, J., Jin, S.V. and Kim, J. (2017) "Uses and gratifications of social networking sites for bridging and bonding social capital: A comparison of Facebook, Twitter, Instagram, and Snapchat", Computers in Human Behavior, Vol. 72, 115-122.

Pöyry, E., Parvinen, P. and Malmivaara, T. (2013) "Can we get from liking to buying?

Behavioral differences in hedonic and utilitarian Facebook usage", Electronic Commerce Research and Applications, Vol. 12 No. 4, pp. 224-235.

PwC (2018) Clothing and footwear. Retrieved from https://www.pwc.com/gx/en/industries/retail-consumer/total-retail/total-retailcategories.html (accessed February, 21, 2018).

PwC (2017) La relación con el cliente omnicanal en el sector moda en España. Retos $y$ oportunidades, Enero 2016 [The relationship with the omnichannel customer in the fashion sector in Spain. Challenges and opportunities, January, 2016, available at: $\quad$ www.pwc.es/es/publicaciones/retail-y-consumo/assets/moda-por un-tuborelacion-cliente-omnicanalsector-moda.pdf (accessed January 9, 2018).

Raacke, J. and Bonds-Raacke, J. (2008) "MySpace and Facebook: applying the uses and gratifications theory to exploring friend-networking sites.", Cyberpsychology \& Behavior, Vol. 11 No 2, pp. 169-74.

Retrieved from https://www.pwc.es/es/publicaciones/retail-y-consumo/assets/modapor-un-tubo-relacion-cliente-omnicanal-sector-moda.pdf $\quad$ (accessed January, 9, 2018).

Rubin, A. M. (2009) "Uses and gratifications perspective on media effects" in J. Bryant, J. and Oliver, M.B. (Eds), Media effect: Advances in theory and research (3rd ed). Routledge, New York, NY, pp. 165-184.

Ruggiero, T.E. (2000) "Uses and gratifications theory in the 21st century", Mass Communication and Society, Vol. 3 No. 1, pp. 3-37. 
Ruiz-Mafe, C., Martí-Parreño, J. and Sanz-Blas, S. (2014) "Key drivers of consumer loyalty to Facebook fan pages", Online Information Review, Vol. 38 No. 3, pp. 362-380.

Satorra, A. and Bentler, P. M. (2010) "Ensuring positiveness of the scaled diff erence chi-square test statistic", Psychometrika, Vol. 75 No. 2, pp. 243-248.

Shao, G. (2009) "Understanding the appeal of user- generated media: a uses and gratification perspective", Internet Research, Vol. 19 No. 1, pp. 7-25.

Sirgy, M.J. (1982) "Self-concept in consumer behavior: A critical review", Journal of Consumer Research, Vol. 9 No. 3, pp. 287-300.

Sirgy, M.J. (1985) "Using self-congruity and ideal congruity to predict purchase motivation", Journal of Business Research, Vol. 13 No. 3, pp. 195-206.

Sirgy, M. J., Grewal, D., Mangleburg, T.F., Park, J., Chon, K. S., Claiborne, C. B., Johar, J. S. and Berkmand, H. (1997) "Assessing the predictive validity of two methods of measuring self-image congruence", Journal of the Academy of Marketing Science, Vol. 25 No. 3, pp. 229-241.

Sirgy, M.J., Grewal, D. and Mangleburg, T. (2000) "Retail environment, selfcongruity, and retail patronage: an integrative model and research agenda", Journal of Business Research, Vol. 49 No. 2, pp. 127-38.

Sirgy, M. J. and Samli, A.C. (1985) "A path analytic model of store loyalty involving self-concept, store image, geographic loyalty, and socioeconomic status", Journal of the Academy of Marketing Science, Vol. 13 No. 3, pp. 265-291.

$\mathrm{Su}$, N. and Reynolds, D. (2017) "Effects of brand personality dimensions on consumers' perceived self-image congruity and functional congruity with hotel brands", International Journal of Hospitality Management, Vol. $66 \mathrm{~N}^{\mathrm{o}}$, pp. 1-12.

Sun, J., Sheng, D., Gu, D., Du, J.T. and Min, C. (2017), "Understanding link sharing tools continuance behavior in social media", Online Information Review, Vol. 41 No. 1, pp. 119-133.

Tariq, J., Sajjad, A., Usman, A. and Amjad, A. (2017) "The role of intentions in facebook usage among educated youth in Pakistan: An extension of the theory of planned behavior", Computers in Human Behavior, Vol. 74, pp. 188-195.

Touchette, B., Schanski, M. and Lee, S-E. (2015) "Apparel brands' use of Facebook: An exploratory content analysis of branded entertainment", Journal of Fashion Marketing and Management, Vol. 19 No. 2, pp. 107-119.

Tsai, H-T. and Huang, H-C. (2007) "Determinants of e-repurchase intentions: an integrative model of quadruple retention drivers", Information \& Management, Vol. 44 No. 3, pp. 231-239.

Wei, H-L., Lin, K-Y, Lu, H-P. and Chuang, I-H. (2015) "Understanding the intentions of users to 'stick' to social networking sites: a case study in Taiwan", Behaviour \& Information Technology, Vol. 41 No. 1, pp. 119-133.

Wu, C-C., Huang, Y. and Hsu, C-L. (2014) "Benevolence trust: a key determinant of user continuance use of online social networks", Information Systems E-Business Management, Vol. 12 No. 2, pp. 189-211.

Wu, J-H., Wang, S-C. and Tsai, H-H. (2010) "Falling in love with online games: the uses and gratifications perspective", Computers in Human Behavior, Vol 26 No. 6, pp. 1862-1871.

$\mathrm{Xu}, \mathrm{C}$., Ryan, S., Prybutok, V. and Wen, C. (2012) "It is not for fun: an examination of social network site usage", Information \& Management, Vol. 49 No. 5, pp. 210217. 
Zara (2017a) In Facebook [Fan Page]. Available at: https://www.facebook.com/ZARA-542604459258146/?ref=ts\&fref=ts $\quad$ (accessed

January, 17, 2017)

Zara (2017b) In Instagram [Fan Page]. Available at: https://www.instagram.com/zara/ (accessed January, 17, 2017).

Zhang, Y., Trusov, A., Stephen, A.T. and Jamal, Z. (2017) “Online shopping and social media: friends and foes", Journal of Marketing, Vol. 81 No. 6, pp 24-41.

Zhao, L., Yin, J. and Song, Y. (2016) "An exploration of rumor combating behavior on social media in the context of social crises", Computers in Human Behavior, Vol. 58, pp. 25-36.

Zhou, T. (2011) "Understanding online community user participation: a social influence perspective", Internet Research, Vol 21 No. 1, pp. 67-81. 